This document is confidential and is proprietary to the American Chemical Society and its authors. Do not copy or disclose without written permission. If you have received this item in error, notify the sender and delete all copies.

\title{
Triethylenetetramine dihydrochloride: Interactions and Conformations in two Anhydrous Structures and a Hydrate
}

\begin{tabular}{|r|l|}
\hline Journal: & Crystal Growth \& Design \\
\hline Manuscript ID: & Draft \\
\hline Manuscript Type: & Article \\
\hline Date Submitted by the Author: & n/a \\
\hline Complete List of Authors: & $\begin{array}{l}\text { Henriet, Théo; Etablissement Pharmaceutique de I'Assistance Publique- } \\
\text { Hôpitaux de Paris, Agence Générale des Equipements et Produits de Santé } \\
\text { Nicolai, Beatrice; Université Paris Descartes, } \\
\text { Ghaddar, Carine; Etablissement Pharmaceutique de I'Assistance Publique- } \\
\text { Hôpitaux de Paris, Agence Générale des Equipements et Produits de Santé } \\
\text { Barrio, Maria; Universitat Politècnica de Catalunya, Departament de Fisica i } \\
\text { Enginyeria Nuclear } \\
\text { Do, Bernard; Etablissement Pharmaceutique des Hôpitaux de Paris, } \\
\text { Yagoubi, Najet; Université Paris Sud, Faculté de Pharmacie } \\
\text { Tamarit, Josep Lluis; Universitat Politècnica de Catalunya, Departament de } \\
\text { Fisica i Enginyeria Nuclear } \\
\text { Rietveld, Ivo; Université Paris Descartes, Pharmacy }\end{array}$ \\
\hline
\end{tabular}




\section{Triethylenetetramine dihydrochloride: Interactions and Conformations in two Anhydrous Structures and a Hydrate}

Théo Henriet ${ }^{\mathrm{a}, \mathrm{b}}$, Béatrice Nicolaïc, Carine Ghaddara, Maria Barriod, Bernard Do ${ }^{\mathrm{a}}$, Najet Yagoubib, Josep-Lluís Tamaritd, Ivo B. Rietveldc,*

a Etablissement Pharmaceutique de l'Assistance Publique-Hôpitaux de Paris, Agence Générale des Equipements et Produits de Santé, 7, rue du Fer à Moulin, 75005 Paris, France

b Matériaux et Santé (EA 401), Faculté de Pharmacie, Université Paris Sud, 5, Rue Jean-Baptiste Clément, 92296, Chatenay-Malabry, France

c Laboratoire de Chimie Physique, Faculté de Pharmacie, Université Paris Descartes, 4, Avenue de l’Observatoire, 75006 Paris, France

d Grup de Caracterització de Materials (GCM), Departament de Física i Enginyeria Nuclear, Universitat Politècnica de Catalunya, ETSEIB, Diagonal 647, 08028 Barcelona, Spain

*Corresponding author: ivo.rietveld@parisdescartes.fr, tel.: +33 153739675 


\begin{abstract}
Triethylenetetramine is a polyamine type chelating ligand for copper (II), which is currently used, mainly in its dihydrochloride form, as an alternative to D-penicillamine against Wilson's disease. Because knowledge about the solid-state behavior of pharmaceuticals is a prerequisite for the development of an effective dosage form, the crystal structures of two triethylenetetramine dihydrochloride polymorphs have been determined and the infrared spectra and thermal expansion have been studied. No suitable crystals could be obtained of the two anhydrous forms, for which the structures have been solved from X-ray powder diffraction. Form I is monoclinic $P 21 / n$ with the cell parameters $a=11.0475(4) \AA, b=$ 4.87475(16) $\AA, c=11.1178(4) \AA$, and $\beta=106.9826(13)^{\circ}$ leading to $V=572.63(3) \AA^{3}$ with $Z=$ 2. Form II is also monoclinic $P 21 / c$ with cell parameters $a=10.6734(6) \AA, b=12.3613(6) \AA, c$ $=9.8479(7) \AA$, and $\beta=115.985(3)^{\circ}$ leading to a unit-cell volume of $V=1167.95(12) \AA^{3}$ with $Z$ $=4$. A recurring structural element is a ionic interaction between two chloride ions and two ammonium groups each organized in a diamond pattern present in the dihydrate (the salt is hygroscopic) and anhydrous form I. The molecular conformations are different in both anhydrous forms and in the dihydrate. Comparison of the thermal expansions demonstrates that form I has the smallest thermal expansion and thus possesses the strongest intermolecular interactions.
\end{abstract}




\section{Introduction}

The dihydrochloride salt of triethylenetetramine $\left(N^{1}, N^{2}\right.$-bis(2-aminoethyl)-1,2ethanediamine, hydrochloride (1:2) and here abbreviated with TETA·2HCl, Figure 1), is a polyamine type chelating ligand for copper (II) and currently used as an alternative to Dpenicillamine against Wilson's disease. ${ }^{1}$ Due to its activity on copper homeostasis, TETA $2 \mathrm{HCl}$ is also being tested for numerous applications such as diabetes mellitus, ${ }^{2}$ Alzheimer's $^{\prime}$ disease, ${ }^{3}$ and even cancer. ${ }^{4}$

TETA was first synthetized in Germany in 1861 and in 1896 prepared as a dichloride salt. ${ }^{5}$ Its chelating activity was studied in $1925 . .^{5}$ Because TETA possesses four equally spaced nitrogen atoms, it fits the square-planar geometry in which $\mathrm{Cu}(\mathrm{II})$ is most stable. It strongly binds $\mathrm{Cu}(\mathrm{II})$ with a dissociation constant in the order of $10^{-15} \mathrm{~mol} / \mathrm{L}$ at $\mathrm{pH} 7.0 .5$ For medical purposes, TETA has been used mainly in the form of the dihydrochloride salt, which is very soluble in water. ${ }^{5,6}$

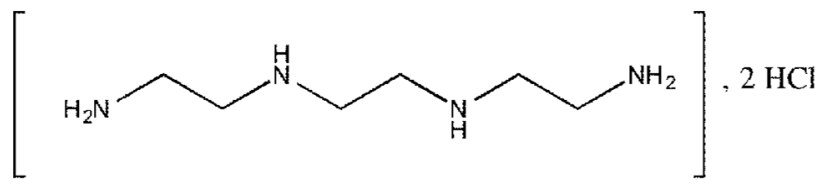

Figure 1. Chemical structure of triethylenetetramine dihydrochloride

Several TETA salts have been studied and a number of crystal structures has been solved: tetrafumarate trihydrate, ${ }^{7}$ disuccinate, ${ }^{7,8}$ tetramaleate dihydrate, ${ }^{7,8}$ tetrafumarate tetrahydrate, ${ }^{8}$ tetraparatoluenesulfonate tetrahydrate, ${ }^{9}$ and dinitrate. ${ }^{9}$ However, even though this substance has been known for over a century, the crystal structure of the TETA.2HCl dihydrate was only solved in 2000. ${ }^{10}$ The crystal structure has been reported in a study on a number of polyamine salts with halogen ions $\mathrm{Cl}^{-}, \mathrm{Br}^{-}$, and $\mathrm{I}^{-} .10 \mathrm{TETA} \cdot 2 \mathrm{HCl}$ dihydrate was found to be isostructural with TETA.2HBr dihydrate and TETA.2HI dihydrate. They crystallize in the monoclinic space group $P 21 / c$ with $Z=4$. The TETA chains are linear. Twelve hydrogen bonds are present per formula unit (leading to six unique hydrogen bonds as the asymmetric unit only contains half a TETA molecule). The chloride anions are fourcoordinate and form the apex of a pyramid. The two additional protons on TETA are found 
on the amine end groups as is expected considering the pKa values of the hydrochloride and the amino groups. ${ }^{10,11}$

The existence of 2 polymorphs of anhydrous TETA $2 \mathrm{HCl}$ have been reported; form I is characterized by a melting range between $111^{\circ} \mathrm{C}$ to $132^{\circ} \mathrm{C}$ and form II by a melting range between $106^{\circ} \mathrm{C}$ to $126^{\circ} \mathrm{C} .1^{2}$ The crystal structures have never been elucidated, however. They will be presented in this paper together with their thermal expansion. In addition, the structures will be compared with that of the dihydrate. Infrared spectra of the two polymorphs will be provided too.

\section{Material and methods}

\subsection{Materials}

Triethylenetetramine dihydrochloride (99.4\%, $\mathrm{C}_{6} \mathrm{H}_{20} \mathrm{~N}_{4} \mathrm{Cl}_{2}, 219.16 \mathrm{~g} \mathrm{~mol}^{-1}$ ) was purchased from Aldrich (Steinheim, Germany) and used as such. Crystals were grown by slow evaporation from various solvents, including ethanol, acetone, dioxane, isopropanol, ethyl acetate and THF. All solvents were of analytical grade with purity $\geq 99 \%$. From all solvents, crystals of the known hydrated form were obtained. ${ }^{10}$ As the commercial powder, form I, did not contain water, it was decided to solve the structure from X-ray powder diffraction data. A second polymorph, form II, could only be obtained by melting the commercial sample and recrystallization from the melt by quenching the liquid at ambient temperature. Therefore, also the structure of form II has been solved from X-ray powder diffraction as described below.

\subsection{High-resolution X-ray powder diffraction}

X-ray powder diffraction was performed on a transmission mode diffractometer using Debye-Scherrer geometry equipped with a cylindrical position-sensitive detector (CPS120) from INEL (France) containing 4096 channels $\left(0.029^{\circ} 2 \theta \text { angular step }\right)^{13}$ with monochromatic $\mathrm{Cu}-\mathrm{K} \alpha_{1}(\lambda=1.54061 \AA)$ radiation. For the measurements as a function of temperature, a liquid nitrogen 700 series Cryostream Cooler from Oxford Cryosystems (United Kingdom) was used. 
Lightly ground specimens were introduced in a Lindemann capillary (0.7 $\mathrm{mm}$ diameter) rotating perpendicularly to the X-ray beam during the experiments to improve the average over the crystallite orientations. Room temperature data were collected for at least 12 hours per polymorph. For the temperature dependent measurements in the range from $100 \mathrm{~K}$ up to the respective melting points of phases I and II, the sample temperature was equilibrated for about $15 \mathrm{~min}$ followed by an acquisition time of ca. 1 hour at each temperature. The heating rate in between data collection was $1.33 \mathrm{~K} \mathrm{~min}^{-1}$. For phase II, a specimen of phase I mixed with Lindemann glass was molten in a Lindemann capillary of $1.0 \mathrm{~mm}$ then cooled down to $293 \mathrm{~K}$ and left to recrystallize overnight after which the X-ray data were collected as described above. Samples prepared outside the capillary contained consistently some phase I.

\subsection{Structure solution of forms I and II from powder diffraction}

For the structure solutions, the program DASH ${ }^{14}$ and TOPAS-Academic ${ }^{15}$ were employed and the powder pattern was truncated to $52.6^{\circ}$ in $2 \theta\left(\mathrm{Cu} K \alpha_{1}\right)$, corresponding to a real-space resolution of $1.75 \AA$ A. The background was subtracted with a Bayesian high-pass filter. ${ }^{16}$ Peak positions for indexing were obtained by fitting with an asymmetry-corrected pseudo-Voigt function. ${ }^{17,18}$

\subsubsection{Form I}

Twenty-one peaks were indexed with the indexing program DICVOL04. ${ }^{19-21}$ A monoclinic unit cell was obtained with figures of merit $\mathrm{M}(21)=15.7$ and $\mathrm{F}(21)=24.5(0.0138,62)$. Pawley refinement was used to extract integrated intensities and their correlations, from which the space group was determined using Bayesian statistical analysis. ${ }^{22}$ The space group $P 2_{1} / n$ was returned as the most probable option. It was the space group with the highest symmetry. It resulted in a Pawley $\chi^{2}$ of 2.46. Simulated annealing was used to solve the crystal structure from the powder pattern in direct space. The starting molecular geometry was taken from the published dihydrate structure from the CSD (reference code XAHWOS), ${ }^{10}$ and only half of the triethylenetetramine molecule was used considering the unit-cell volume $\left(573 \AA^{3}\right)$ and the symmetry elements. In 30 simulated annealing runs, the same crystal structure was found 30 times. The profile $\chi^{2}$ of the best solution was 8.81 , which is less than four times the Pawley $\chi^{2}$; these are good indications that the correct solution has been found. 
For the Rietveld refinement, data out to $90^{\circ} 2 \theta$ were used, which corresponds to $1.1 \AA$ realspace resolution. The Rietveld refinement was carried out with TOPAS-Academic. ${ }^{15}$ Bond lengths, bond angles and planar groups were subjected to suitable restraints, including bonds to $\mathrm{H}$ atoms, based on the distances found in the structure XAHWOS. A global $B_{\text {iso }}$ was refined for all non-hydrogen atoms, with the $B_{\text {iso }}$ of the hydrogen atoms constrained at 1.2 times the


Dollase formula ${ }^{23}$ was tried for directions (100), (010) and (001). No difference to the $R_{\mathrm{wp}}$ value was observed. The molecular geometry was checked with Mogul, ${ }^{24}$ which compares each bond length and bond angle to corresponding distributions from single-crystal data.

\subsubsection{Form II}

20 peaks were indexed with the indexing program DICVOL04. ${ }^{19-21} \mathrm{~A}$ monoclinic unit cell was obtained with figures of merit $M(20)=12.1$ and $F(20)=27.3(0.0175,42)$. The exact same monoclinic unit cell was also found by TOPAS Academic. ${ }^{25}$ Pawley refinement was used to extract integrated intensities and their correlations, from which the space group was determined using Bayesian statistical analysis. ${ }^{22}$ The space group $P 21 / c$ was returned as the most probable option, which was the one with the highest symmetry. It resulted in a Pawley $\chi^{2}$ of 2.73. Simulated annealing was used to solve the crystal structure from the powder pattern in direct space. In first instance, this did not lead to any solution. Taking into consideration that form II needed to be prepared in the capillary, preferred orientation was included into the analysis. After some trial and error, the preferred orientation direction (13 0) appeared to return the best result and it was used for the simulated annealing. In 100 runs, the 20 crystal structures with the lowest $\chi^{2}$ were the same. The profile $\chi^{2}$ of the best solution was 7.82, which is about three times the Pawley $\chi^{2}$; these are reasonable indications that the correct solution has been found.

For the Rietveld refinement, data out to $90^{\circ} 2 \theta$ were used. A preferred-orientation correction with the March-Dollase formula ${ }^{23}$ was used with direction (1 30 ). Other directions were tried, but did not lead to a better fit. The molecular geometry was checked with Mogul,24 which compares each bond length and bond angle to corresponding distributions from single-crystal data. 
Supplementary crystallographic data can be found in the CCDC, deposit numbers 1014992 and 1014993 for form I and form II respectively, and obtained free of charge from the Cambridge Crystallographic Data Centre via www.ccdc.cam.ac.uk/data request/cif/.

\subsection{Parametric Pawley and Rietveld refinements}

The lattice parameters as a function of temperature have been determined with Pawley fits to the known unit cells using TOPAS Academic. ${ }^{15}$ The X-ray patterns for each temperature were fitted simultaneously with global diffraction setup constants and a global zero error. For the parametric Rietveld refinements, the atom coordinates of the structure were also defined globally, whereas the unit-cell parameters were allowed to refine independently for each temperature.

\subsection{Hirshfeld Surfaces and fingerprint plots.}

Calculations were performed with CrystalExplorer v3.02026,27 with the experimental crystal geometries as input. ${ }^{10}$ Distance $d_{i}$ is defined as the distance from the Hirshfeld surface to the nearest interior atom, and $\mathrm{d}_{\mathrm{e}}$ is the distance from the surface to the nearest exterior atom. Plots of $d_{e}$ against $d_{i}$, called fingerprint plots, offer the possibility to classify crystals by the nature of their intermolecular interactions and to rapidly identify structural similarities. ${ }^{28}$

\subsection{Isobaric thermal expansion tensor}

The anisotropy of the intermolecular interactions can be investigated with the isobaric thermal expansion tensor, which is a measure of how the interactions change with temperature. ${ }^{29}$ A small value for a tensor eigenvalue is commonly referred to as a "hard" direction and a large value as a "soft" direction. ${ }^{30}$ The tensor was calculated by PASCAL software ${ }^{31}$ and was drawn by Wintensor. ${ }^{32}$

\subsection{Infrared spectrometry}

Infrared spectrometry was carried out with a Fourier transform Perkin-Elmer Septum spectrometer 1000 using the Spectrum 1000 analysis software. Spectra were recorded at room temperature from 500 to $4000 \mathrm{~cm}^{-1}$. Samples were measured directly in the solid state without the need of a matrix. 


\section{Results}

\subsection{Crystal structures of forms I and II}

The Rietveld refinement for the structure of form I progressed smoothly and produced a good fit with $\chi^{2}=1.585, R_{\mathrm{p}}^{\prime}=11.523, R_{\mathrm{wp}}^{\prime}=11.091$ (values after background correction), $R_{\mathrm{p}}=$ 1.903 and $R_{\mathrm{wp}}=2.512$ (values before background subtraction). $B_{\text {iso }}$ refined to $1.47(9) \AA^{2}$. The cell parameters of phase I and its structure solution data by powder diffraction can be found in Table 1. The structure is monoclinic, space group $P 2_{1} / n$ and has a unit-cell volume of $572.64(3) \AA^{3}$ with $Z=2$ and $Z^{\prime}=1 / 2$. The result of the Rietveld refinement is shown in Figure $2 \mathrm{a}$ and the crystal packing in Figure $2 \mathrm{~b}$.

For phase II, the Rietveld refinement produced a reasonable fit with $\chi^{2}=1.935, R_{\mathrm{p}}^{\prime}=27.473$, $R_{\text {wp }}^{\prime}=22.528$ (values after background correction), $R_{\mathrm{p}}=2.114$ and $R_{\mathrm{wp}}=2.959$ (values before background subtraction). $B_{\text {iso }}$ refined to $1.1(2) \AA^{2}$. The high R-values are the result of preferred orientation that has been difficult to fully compensate for. The cell parameters of phase II, determined with powder diffraction, can be found in Table 1. The structure is monoclinic, space group $P 2_{1} / c$ and has a unit-cell volume of 1167.95(12) $\AA^{3}$ with $Z=4$ and $Z^{\prime}$ $=1$. The result of the Rietveld refinement is shown in Figure 2a and the crystal structures in Figure 2c. 

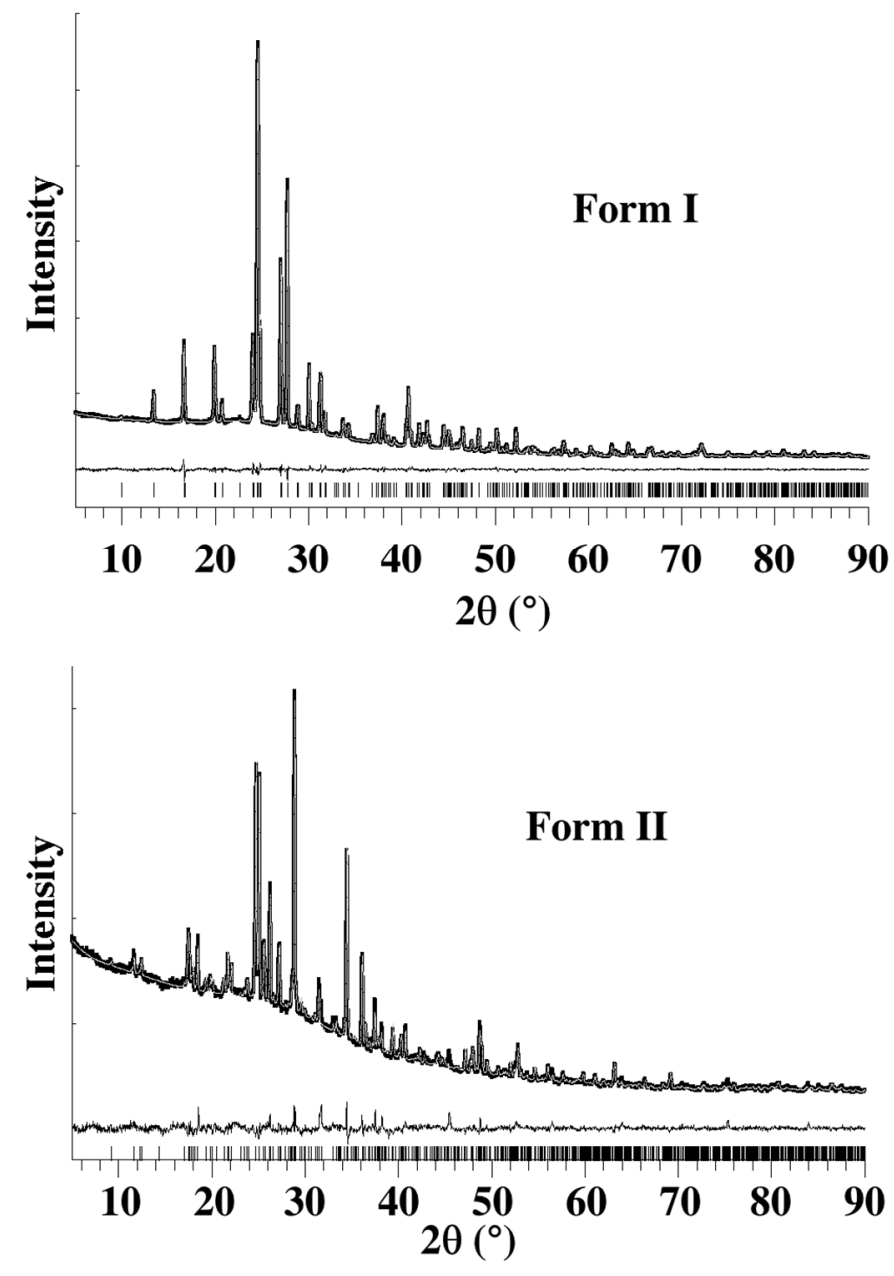

a

b
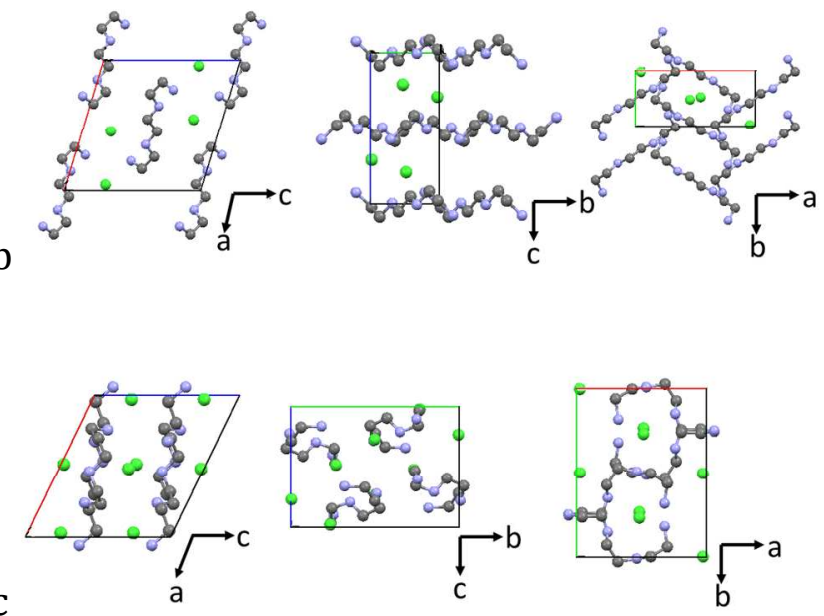

Figure 2. Results of the structure resolutions by X-ray powder diffraction a. Rietveld refinements against the powder diffraction patterns b. Crystal structure of form I c. Crystal structure of form II. Hydrogen atoms omitted for clarity. 


\subsection{Powder diffraction data as a function of temperature}

The cell parameters and the unit-cell volumes of form I, form II, and the dihydrate increase linearly with temperature (Table 2). The volumes of the asymmetric unit (in $\AA^{3}$ ) as a function of temperature for the three forms are given by:

form I $(Z=2): \quad V_{\mathrm{I}} / Z=\quad 282.04(8)+0.0172(3) T$

form II $(Z=4): \quad V_{\text {II }} / Z=\quad 282(1)+0.039(3) T$

dihydrate $(Z=2): \quad V_{2 \mathrm{H} 2 \mathrm{O}} / Z=\quad 319.9(2)+0.0337(5) T$

The eigenvalues of the thermal expansion tensor of forms I and II, and the dihydrate are compiled in Table 3. The 3D tensors can be found in Figure 3. In the 3 structures, the thermal expansion is constant with temperature but not isotropic. The maximum expansion is along $\mathbf{e}_{3}$ for forms I and II and is comparatively large for form II. The minimum expansion can be found along $\mathbf{e}_{\mathbf{1}}$ in the 3 forms.
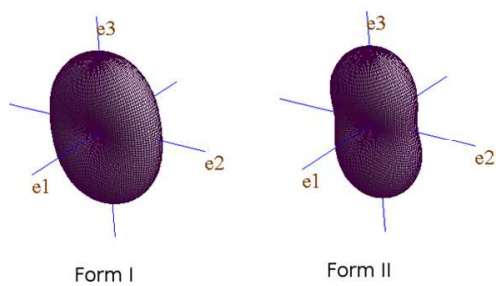

Form II

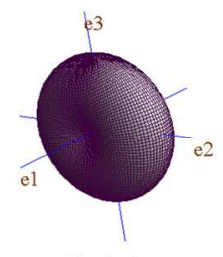

dihydrate

Figure 3. Graphical representation of the thermal expansion tensors of forms I, II, and the dihydrate at $300 \mathrm{~K}^{32}$

\subsection{Infrared measurements}

The IR spectra of forms I and II are presented in Figure 4 (a list of absorption peaks is provided in the supporting information). In both spectra, the absence of a broad peak around $3600 \mathrm{~cm}^{-1}$ demonstrates the absence of water. The two IR spectra are different as would be expected for conformational polymorphs. They contain characteristic peaks for the ammonium group, confirming the transfer of the hydrochloride proton to the TETA molecule. The N-H stretch (secondary amine and ammonium groups) frequencies are different in forms I and II. This is consistent with the different hydrogen-bond networks for the two polymorphs. Moreover, the N-H frequencies of form I are higher than those of form II (3419 
vs. $3285 \mathrm{~cm}^{-1}$ ). This is an indication for the increase in strength of the hydrogen bonds in form I.

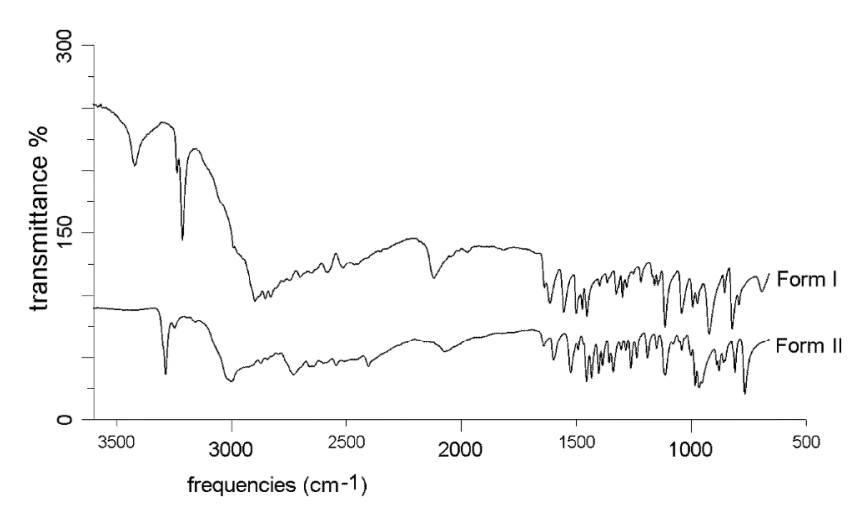

Figure 4. Infrared transmittance spectra of the two TETA $2 \mathrm{HCl}$ polymorphs I and II. Spectra are shifted for clarity

\section{Discussion}

\subsection{Conformations}

TETA is a flexible molecule with seven torsion angles (Table 4). In the dihydrate, the molecule is linear (Figure 5) and its molecular center is located on an inversion center of the unit cell. Therefore, there are only 3 independent torsion angles and because the molecule is linear all the angles have a value of approximately $180^{\circ}$. The point group symmetry of the molecule is $C_{i}$, or $D_{2 h}$ disregarding the hydrogen atoms, as the molecule is linear. The same linear configuration has been observed for the tetrafumarate trihydrate salt ${ }^{7}$ and for the salt with TETA and $p$-toluenesulfonic acid (1:4). ${ }^{9}$ In these two salts all four amine groups are protonated, however.

The point group symmetry of the TETA molecule in form I is $C_{i}$, for it is also located on an inversion center of the unit cell. However, the $D_{2 h}$ symmetry is lost, because the molecule is not completely linear; the torsion angle N1-C1-C2-N2 is $-73.7(3)^{\circ}$ (Figure 5 and Table 4). Its configuration can also be found in the salt of TETA with succinate (ratio 1:2), in which all four amine groups are protonated. ${ }^{7}$ In form II, the molecule is neither linear (Figure 4) nor 
placed on an inversion center. The torsion angles all differ and range from 44.7(1.6) to $163.5(1.2)^{\circ}$ in absolute values. This configuration has not been reported in the literature.
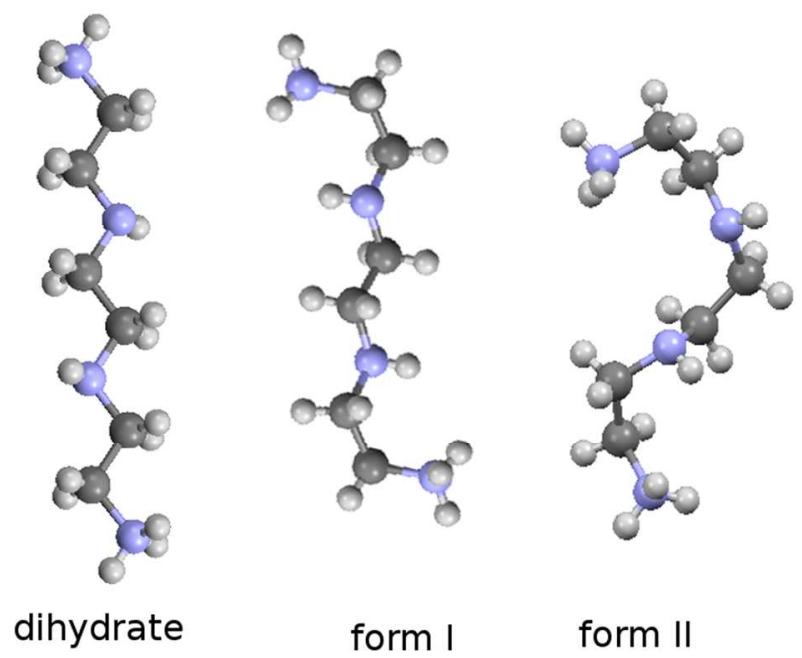

form I form II

Figure 5. Conformations of TETA in the dihydrate (left-hand side), form I (center), and form II (right-hand side)

\subsection{Packing in the two anhydrous TETA $2 \mathrm{HCl}$ polymorphs compared to the dihydrate} In form I and in the dihydrate, the asymmetric unit contains only half a TETA molecule and a chloride ion (in the case of the dihydrate, the asymmetric unit also contains a water molecule). In form II, the whole TETA molecule and two chloride anions can be found in the asymmetric unit. Even though TETA is used throughout the text, it is clear from all three structures that hydrochloride has donated its proton to the terminal amine groups. Thus TETA in these structures actually refers to TETA $2 \mathrm{H}^{+}$.

The molecular packings of the two anhydrous structures have been presented in Figures $2 \mathrm{~b}$ and 2c. In form I, the TETA molecules are linear, except for the terminal $\mathrm{NH}_{3}{ }^{+}$(see Figure 5). The TETA molecules form layers parallel to the $a b$ plane (Figure 2) with a distance between each other of $c / 2$. Whereas the molecules within each layer are parallel, the molecules of subsequent layers have different orientations; in one layer they are oriented in the direction $\mathbf{a}+\mathbf{b}$ and in the adjacent layer in the direction $\mathbf{a}-\mathbf{b}$ (Figure 2). The chloride ions can be found between the TETA layers in columns along the $b$ axis. The formation of layers separated by anions is an often-recurring element in structures with TETA as many examples can be found in the literature. $7,9,10$ 
In form II, the TETA molecules are sickle shaped instead of linear (Figure 5). As in form I, the TETA molecules form parallel layers (Figure 2) interchanged by chloride columns along the $b$ axis. The distance between the layers is again $c / 2$. As can be seen in Figure 2, chloride columns can also be observed along the $c$ axis, part of them running through a circular area defined by the circular part of two TETA molecules in adjacent layers.

In the dihydrate, layers of TETA molecules can be observed parallel to the $b c$ plane. ${ }^{10}$ Within the layers, adjacent TETA molecules are shifted by half a molecule along the $c$ axis and they possess two specific orientations with a $30^{\circ}$ difference between each other. The water molecules and chloride ions possess their respective columns in between these layers along the $a$ axis. Moreover, also the TETA molecules form columns along the $a$ axis. All three structures represent different packings highlighting the flexibility of the TETA molecule.

\subsection{Intermolecular interactions}

\subsubsection{Hydrogen bonds}

In form I, three unique hydrogen bonds have the terminal amine group $\mathrm{N}_{1} \mathrm{H}_{3}{ }^{+}$as donor (Table 5). N2 on a different TETA molecule is acceptor of one of those. Another hydrogen bond is connected to the chloride ion inside the asymmetric unit and the third one is connected to a chloride ion outside of the asymmetric unit (See Table 5 for the molecular coordinates). It should be mentioned that a slightly weaker hydrogen bond with $\mathrm{N} 2-\mathrm{H}$ as donor is also bound to the chloride ion in the asymmetric unit (see Table 5). This leads to five hydrogen bonds connected to TETA (of which two between TETA and $\mathrm{Cl}^{-}(x, y, z)$ ) in the asymmetric unit and an additional sixth one only connected to the chloride ion in the asymmetric unit. Thus the TETA molecule takes part in ten hydrogen bonds, four of which are with the two adjacent TETA molecules that make up the molecular layers parallel to the $a b$ plane of the unit cell (Figure 6a). The six others are linked to the chloride ions that interconnect the different layers of the TETA molecules (Figure 6b). The chloride ion forms the top of a tetrahedron, which is linked to both N1 and N2 of the same TETA molecule (Figure 6c). This explains the deviating torsion angle (Table 4) of an otherwise linear molecule. Moreover, the chloride ion on top of the tetrahedron of hydrogen bonds possesses above the tetrahedron a triangular interaction with two more hydrogen atoms on two different molecules: H1a $(x+1 / 2,-y+1 / 2, z+1 / 2)$ and $H 2 b(x+1 / 2,-y+1.5, z+1 / 2)$. 
As mentioned above the layers or sheets of TETA molecules are held together by hydrogen bonds, which are described by graph sets such as $C_{1}^{1}(5)$ and $C_{2}^{2}(16)$. The infinite chains formed by the chloride ions are in part described by $\mathrm{C}_{2}^{1}(4)$ and rings formed with two chloride ions are described by $\mathrm{R}^{2}{ }_{4}(8)$ (Figure $\left.6 \mathrm{~b}\right)$. Considering the fact that the distances between the chloride ions and the donors in these rings are small and also that both the chloride ions and the ammonium groups are charged, it must be one of the main backbones of the structure of form I.

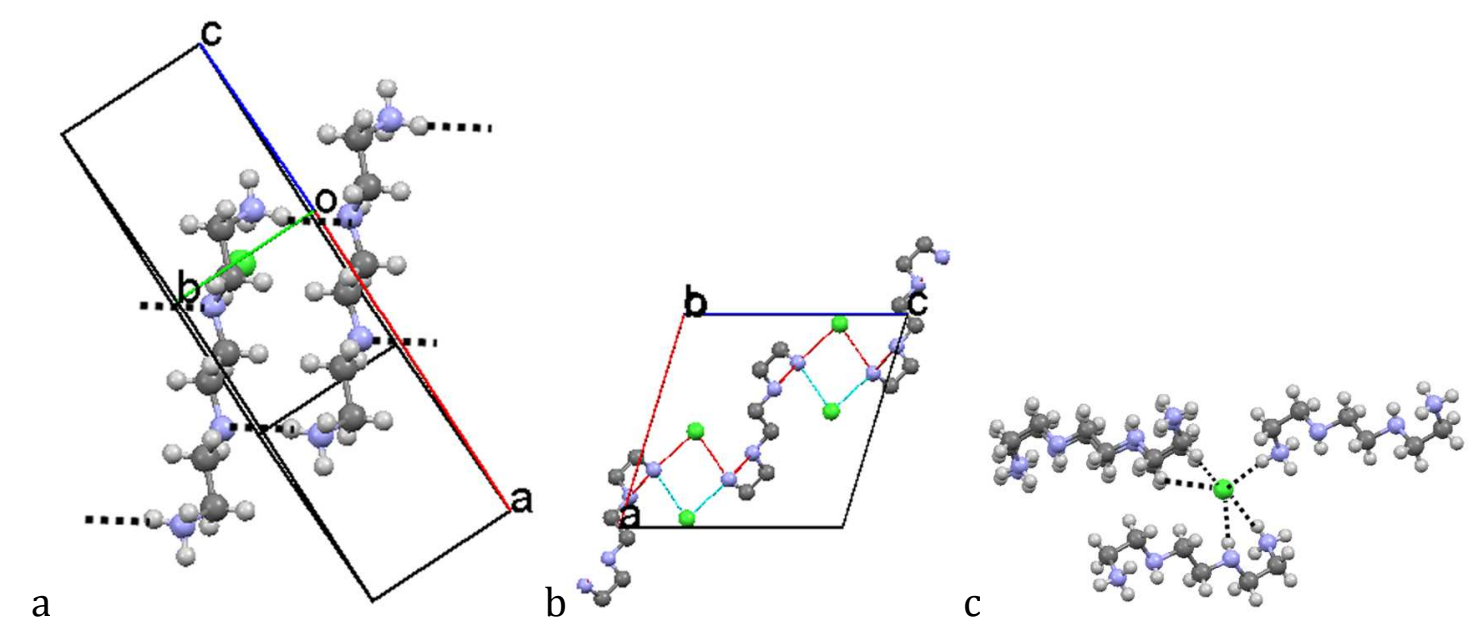

Figure 6. Hydrogen-bond patterns in form I a. between TETA molecules b. Ionic interactions between chloride ions and ammonium groups on TETA molecules (graph set $\mathrm{R}^{2}{ }_{4}(8)$ ) $\mathbf{c}$. Hydrogen bonds and other interactions around the chloride ion

In form II, for which the entire TETA molecule is part of the asymmetric unit, TETA has seven hydrogen bonds, all with chloride ions. The chloride ion $\mathrm{Cl} 1$ possesses four hydrogen bonds and $\mathrm{Cl} 2$ possesses three (Table 5). To both terminal $\mathrm{NH}_{3}{ }^{+}$groups (N1 and $\mathrm{N} 4$ ) two chloride ions are connected. It can be seen in Table 5 that the sickle shape form of the TETA molecules is stabilized by two chloride ions connecting to two different amine groups on a single TETA molecule: one $\mathrm{Cl} 1(-x+1,-y+1,-z+1)$ is linked to $\mathrm{N} 1$ and $\mathrm{N} 3$, if not by hydrogen bond than at least by electrostatic interactions (to N3), and one $\mathrm{Cl} 2(-x+1, y-1 / 2,-z+1 / 2)$ is linked to N3 and N4. The Cl1 ions form tetrahedrons with two molecules linking to N1 and N3 on a single TETA molecule $(-x+1,-y+1,-z+1)$ and to $\mathrm{N} 2$ on another TETA molecule $(x, y, z)$ (Figure 7 ). This tetrahedron is mirrored by a second Cl1 ion $(-x+1,-y+1,-z+1)$, binding to N1 and N3 of 
the other TETA molecule $(x, y, z)$ and to N2 on the first TETA molecule $(-x+1,-y+1,-z+1)$. In addition to the interaction in the shape of a tetrahedron, an additional hydrogen bond to the N1 on a third TETA $(-x+1, y-1 / 2,-z+1 / 2)$ exists.

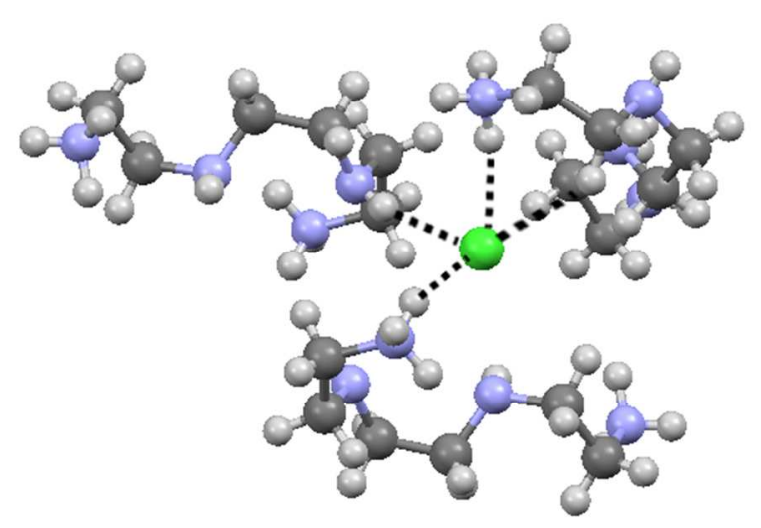

Figure 7. Ionic and hydrogen-bond interactions of Cl1 in form II.

$\mathrm{Cl} 2(-x+1, y-1 / 2,-z+1 / 2)$ is linked to N4 on two different TETA molecules $(x, y, z$ and $-x, y-1 / 2$, $-z+1 / 2$ ), forming an infinite chain with graph set $\mathrm{C}^{1}{ }_{2}(7)$. In addition, $\mathrm{Cl} 2$ is involved in a hydrogen bond to $\mathrm{N} 3$ on one of those TETA molecules $(x, y, z)$. The chloride ions stabilize the sickle shape of the TETA molecules and keep the structure together by interconnecting the TETA molecules by hydrogen bonds and electrostatic interactions.

For the dihydrate, each TETA molecule is involved in twelve hydrogen bonds, which means six in the asymmetric unit (Table 5, the asymmetric unit contains only half a TETA molecule). Four hydrogen bonds exist with four different chloride ions and two hydrogen bonds with two different water molecules. No hydrogen bonds exist directly between different TETA molecules. Thus the layers of TETA molecules are linked via the water molecules and the chloride ions. Water is involved in three different hydrogen bonds, two connected to TETA molecules and one to a chloride ion. The chloride ion is the apex of a shallow pyramid formed by four hydrogen bonds involving three TETA molecules $(-x,-y+1,-z+1 ; x+1, y, z ; x+1,-y+$ $1.5,-z-1 / 2)$ and a water molecule $(-x-1,-y+1,-z+1)$ and from this apex another hydrogen bond exists with the ammonium group in the asymmetric unit. More information on the structure of the dihydrate can be found in the literature. ${ }^{10}$ 
In Table 5, it can be observed that the TETA molecule possesses most hydrogen bonds in the dihydrate -twelve in total-, then form I with eight hydrogen bonds, and then form II in which TETA possesses only seven hydrogen bonds. This explains at least in part the ease of TETA to form the dihydrate, as it is thoroughly stabilized by the additional hydrogen bonds.
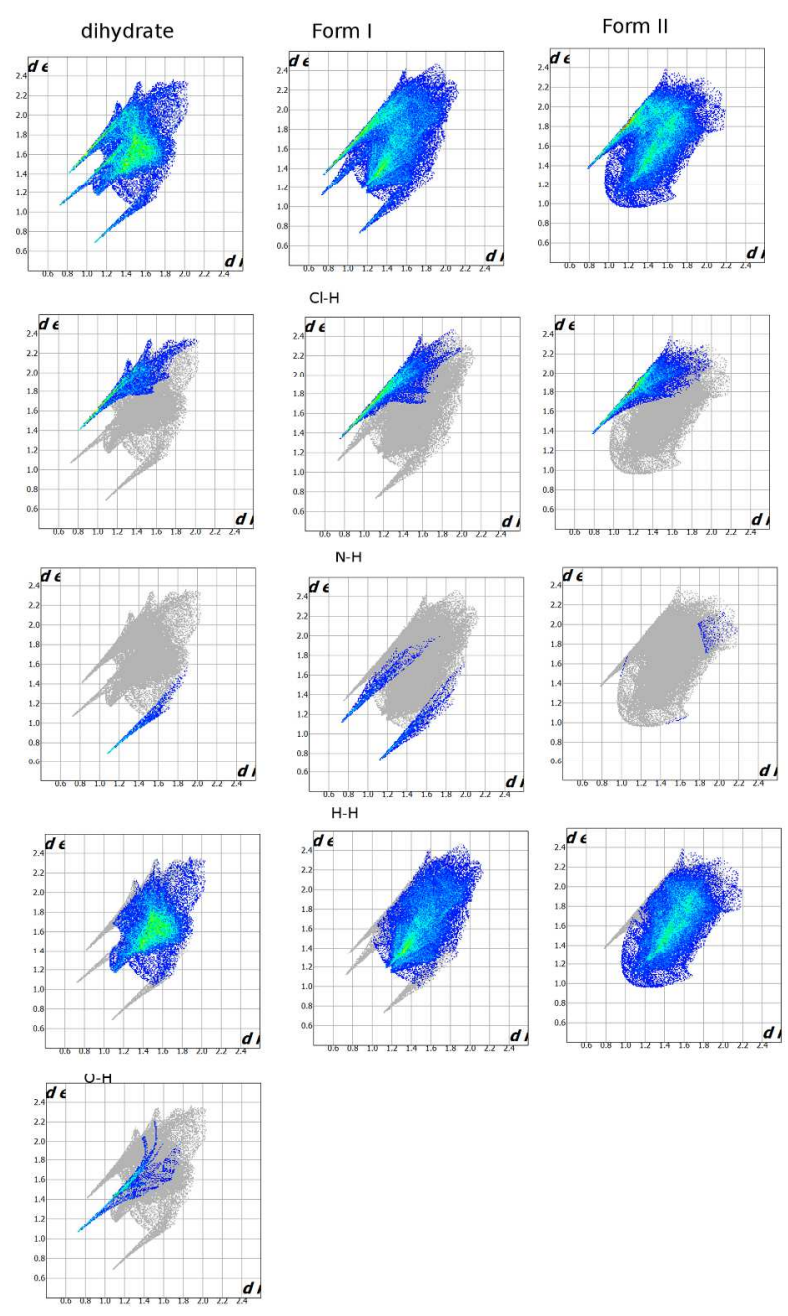

Figure 8. Fingerprint plots ${ }^{28}$ of the TETA molecule in the dihydrate, in form I and in form II. From top to bottom: all intermolecular interactions together, $\mathrm{Cl} \cdots \mathrm{H}$ interactions, $\mathrm{N} \cdots \mathrm{H}, \mathrm{H} \cdots \mathrm{H}$, and $0 \cdots \mathrm{H}$ interactions. The $d_{i}, d_{e}$ occurrence increases from deep blue to light blue.

\subsubsection{Fingerprint plots}

Because the hydrogen bond patterns are complex and different for each form, Hirshfeld surfaces have been calculated for the TETA molecules in the three different structures. To facilitate comparison, the Hirshfeld surfaces have been converted into fingerprint plots. ${ }^{28}$ 
The $\mathrm{Cl} \cdots \mathrm{H}$ interactions (Figure 8, second row from the top) are found in the upper left corner and these interactions are present in all three structures. The strengths (distances) are also equal in each structure, although they seem a bit stronger for form I. This is obviously due to the many hydrogen bonds that are formed between the TETA cations and the chloride anions. Interactions between $\mathrm{N}$ and $\mathrm{H}$ are clearly not important in form II; however in the dihydrate and in form I they are particularly strong (short). The symmetry observed for form I confirms that the interaction between $\mathrm{N}$ and $\mathrm{H}$ occurs between TETA molecules, whereas the single peak in the dihydrate points to the fact that the main $\mathrm{N} \cdots \mathrm{H}$ interaction is due to hydrogen atoms of the water molecules. Strength-wise the interactions are the same, but the relative occurrence of stronger interactions is higher in the dihydrate, as can be judged from the light blue color in the tip of the spike. The $\mathrm{H}-\mathrm{H}$ interactions are important in all three structures. The single spike in the dihydrate corresponds to the $\mathrm{N}-\mathrm{H} \cdots \mathrm{O}$ interaction, which is obviously absent in the two anhydrous forms.

\subsubsection{Thermal expansion}

The thermal expansion is constant over the entire temperature range for the dihydrate, form I, and form II (Table 3). All cell parameters increase linearly within measurement error and the thermal coefficients are positive, confirming that there are no contractions. ${ }^{33,34}$ The coefficients range from 3 to $80 \mathrm{MK}^{-1}$, which is in the same range as those observed for tienoxolol ${ }^{33}$ and a number of tyrosine derivatives. ${ }^{35}$ The expansion is anisotropic, although in the dihydrate $\alpha_{22}$ and $\alpha_{33}$ are virtually the same. In addition, the expansion in the hard direction, the most limited expansion, is much smaller in forms I and II, than in the dihydrate ( $\alpha 11$ being $3.5,4.5$, and $13.0 \mathrm{MK}^{-1}$ respectively). 

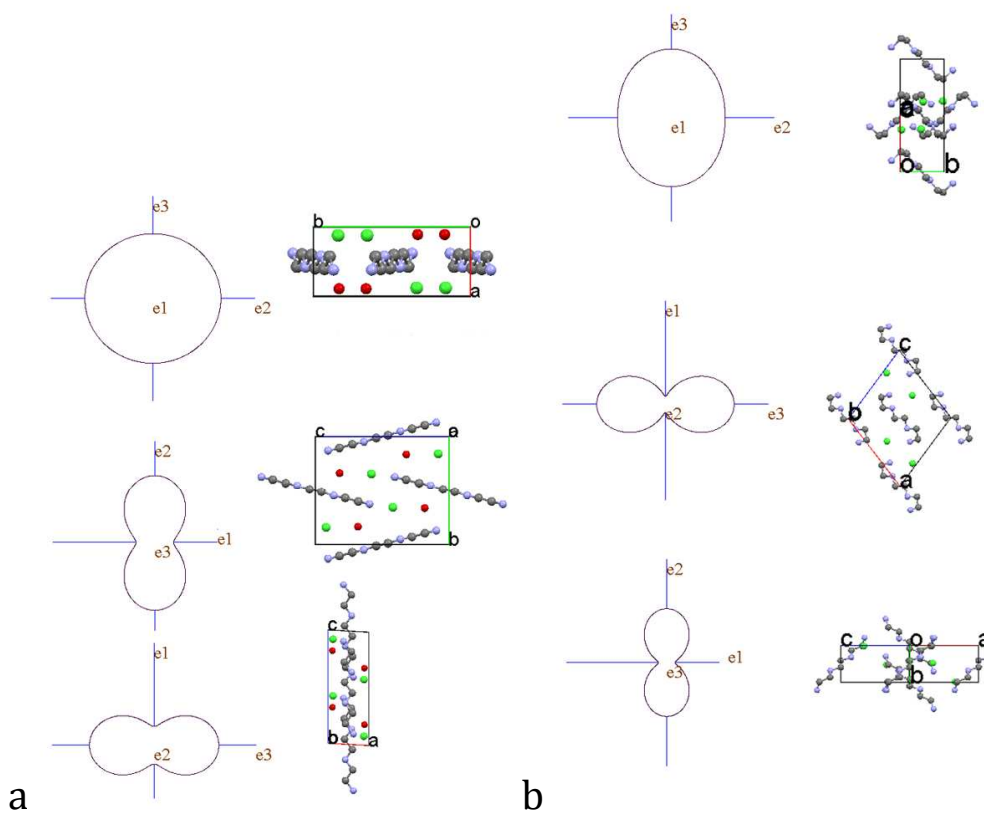

b
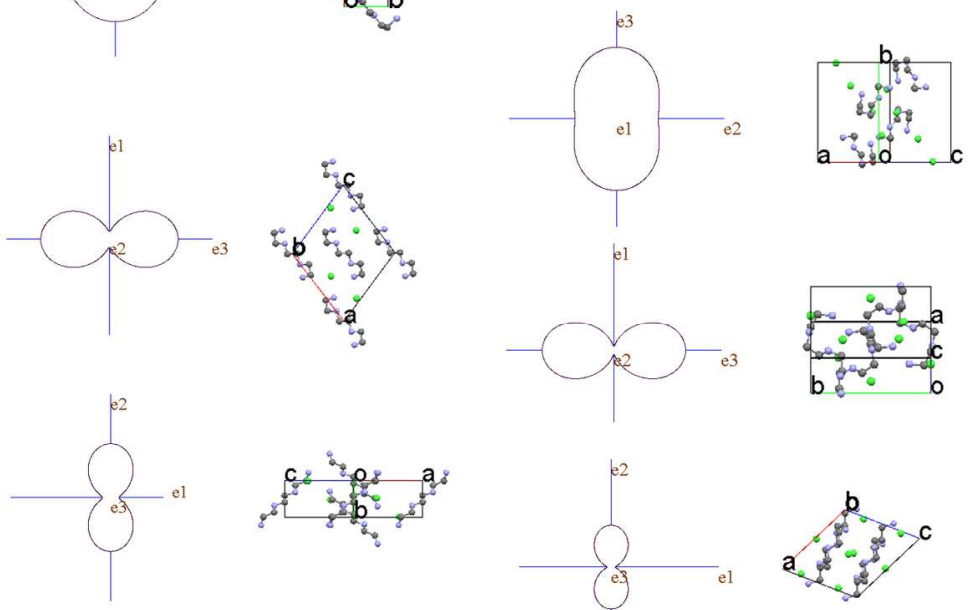

Figure 9. Projections of the thermal expansion tensors in relation to the unit cell a. for the dihydrate, b. for form I, and c. for form II. Hydrogen atoms have been omitted for clarity.

In the dihydrate, the thermal coefficient along $\mathbf{e}_{\mathbf{1}}$ (approximately along the unit-cell $c$ axis) is relatively small with $13.0 \mathrm{MK}^{-1}$ (Table 3, Figure 9a). It corresponds to the hard direction of the crystal, along which the intermolecular interactions are the strongest, in this case the ionic interaction between the chloride ion and the ammonium end groups. They form a diamond shape pattern as can be seen in Figure 10. A proliferation of hydrogen bonds without substantial ionic interactions causes the thermal expansion in the other directions to be fairly isotropic.

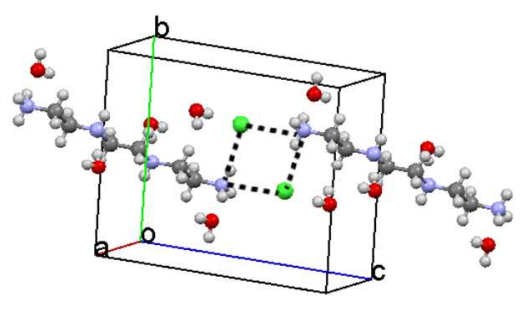

Figure 10. Diamond shape pattern in the dihydrate made up by the ionic interaction involving two chloride ions and two ammonium end groups. 
The thermal expansion is lowest for form I in comparison to the two other forms. The hard direction is $\mathbf{e}_{\mathbf{1}}$ with a tensor coefficient of $3.8 \mathrm{MK}^{-1}$ (Table 3, Figure 9b), which coincides with the line-up of the before-mentioned diamond configuration of two chloride ions and two ammonium groups representing the major ionic interaction in the crystal (Figure 6b). A similar pattern can be seen repeated in the dihydrate (Figure 10), but the interactions involved are weaker considering the thermal expansion coefficients.

Form I's soft direction is along $\mathbf{e}_{3}\left(31.8 \mathrm{MK}^{-1}\right)$ roughly along the main diagonal of the ac plane. Along this direction the layers of TETA are mainly connected by van der Waals interactions; however, each chloride ion interacts relatively strongly (distances of 2.946 and $2.852 \AA$ ) with two hydrogen atoms of two TETA molecules in the adjacent layer. The resulting thermal expansion of $32 \mathrm{MK}^{-1}$ is therefore still relatively low for the soft direction, in particular in comparison with the thermal expansion along $\mathbf{e}_{2}$ equivalent to the $b$ axis of the unit cell. The latter direction contains the double hydrogen bonds between the TETA molecules in the layer along the $b$ axis and it has an expansion coefficient of $25 \mathrm{MK}^{-1}$. The strength of the hydrogen bonds in form I is confirmed by the results obtained by infrared.

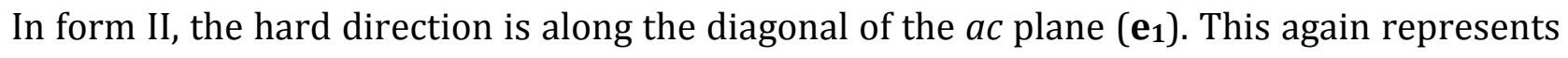
the ionic interaction involving chloride ions linked to ammonium and amino groups on several TETA molecules forming an infinite chain of ionic interaction. Strangely enough the softest direction $\mathbf{e}_{3}$, along $\mathrm{b}$, also contains a ionic infinite chain involving $\mathrm{Cl} 2$ and the ammonium group at the handle side of the sickle shape; however, this chain is buckled and the expansion may be the result of an alignment of the molecules along the $b$ axis.

\section{Conclusion}

The crystal structures of two TETA $2 \mathrm{HCl}$ polymorphs have been determined by X-ray powder diffraction at room temperature. Form I is monoclinic with space group $P 2_{1} / n$ and its unitcell volume is $572.63(3) \AA^{3}$ with $Z=2$. Form II is monoclinic with space group $P 21 / c$ and its unit-cell volume is $1167.95(12) \AA^{3}$ with $Z=4$.

Specific ionic interactions between the ammonium end groups and the chloride ions are a recurring theme in the structures of the two anhydrous forms and the dihydrate, for example 
the diamond pattern formed by two chlorides and two ammonium groups that occur in both the dihydrate and form I. However, the conformations of the TETA molecule are different in all structures. It demonstrates its flexibility. The structures are all distinct, even though they are built up from the same elements. It can also be seen that water is readily incorporated in the structure as the TETA molecules have considerably more hydrogen bonds in the hydrate than in the anhydrous forms. Whereas form I also forms hydrogen bonds between different TETA molecules, form II relies completely on hydrogen bonds with the chloride ion as intermediate. In particular the chloride - ammonium interactions play an important role in all three structures.

Although the dihydrate has by far the most hydrogen bonds, thermal expansion demonstrates that form I is the crystal with the strongest interactions as its thermal expansion is clearly smaller than the other two forms. All structures have strong ionic interactions that can be recognized by the hard directions in the thermal expansion. Extensive hydrogen bond networks mainly control the thermal expansion in the other directions. In this respect it is surprising to observe the high value of $80 \mathrm{MK}^{-1}$ for form II along $\mathbf{e}_{3}$, while there is clearly an infinite chain of ionic interactions in combination with hydrogen bonds. It is probably because the infinite chain is relatively isolated from the other intermolecular interactions and because this chain is buckled providing room for alignment.

\section{Supporting Information}

Infrared absorption frequencies for form I and form II.

\section{References}

(1) Ferenci, P.; Czlonkowska, A.; Stremmel, W.; Houwen, R.; Rosenberg, W.; Schilsky, M., J. Hepatol. 2012, 56(3), 671-685.

(2) Cooper, G. J. S., Curr. Med. Chem. 2012, 19(17), 2828-2860.

(3) Cooper, G. J. S., Drugs 2011, 71(10), 1281-1320.

(4) Liu, J.; Guo, L.; Yin, F.; Zheng, X.; Chen, G.; Wang, Y., Biomed. Pharmacother. 2007, 62(7), 480-485.

(5) Dixon, H. B. F., The chemistry of trientine. In Scheinberg IH, Walshe JM,, Scheinberg, I.; Walshe, J., Eds. University Press in Association with the Fulbright Commission: 1986; pp 23-32.

(6) Lu, J., Molecular cancer therapeutics 2010, 9, 2458-2467. 
(7) Wichmann, K. A.; Boyd , P. D. W.; Söhnel, T.; Allen, G. R.; Phillips , A. R. J.; Cooper, G. J. S., Crystal growth and design 2007, 7(9), 1844-1850.

(8) Jonas, M.; Vaulont, I.; Soi, A.; Schmidt, G. Synthesis of triethylenetetramines. 8394992, 2013.

(9) Junk, P. C.; Smith, M. K., C.R. Chimie 2005, 8(2), 189-198.

(10) Ilioudis, C. A.; Hancock; K.S.B.; Gerganopoulou, D. G.; Steed, J. W., New J. Chem. 2000, 24(10), 787-

798.

(11) Cukrowski, I.; Matta, C. F., Comp. Theor. Chem. 2011, 966, 213-219.

(12) Jonas, M.; Vaulont, I.; Soi, A.; Schmidt, G. Synthesis of triethylenetetramines. 8067641, 2011.

(13) Ballon, J.; Comparat, V.; Pouwe, J., Nucl. Instrum. Methods Phys. Res, Sect. A 17, 213-216.

(14) David, W. I. F.; Shankand, K.; van de Streek, J.; Pidcock, E.; Motherwell, W. D. S.; Cole, J. C., J. Appl; Crystallogr. 2006, 39, 910-915.

(15) Coelho, A. A. TOPAS Academic version 4.1 (Computer Software), Coelho Software: Brisbane, 2007.

(16) David, W. I. F.; Sivia, D. S., J. Appli. Crystallogr. 2001, 34(318-324).

(17) Finger, L. W.; Cox, D. E.; Jephcoat, A. P., J. Appl. Crystallogr. 1994, 27(892-900).

(18) Thompson, P. C., D.E.; Hastings, J. B., J. Appl. Crystallogr. 1987, 20, 79-83.

(19) Boultif, A.; Louer, D., J. Appl. Crystallogr. 1991, 24, 98-993.

(20) Boultif, A.; Louer, D., J. Appl. Crystallogr. 2004, 37, 724-731.

(21) Louer, D.; Louer, M. J., J. Appl. Crystallogr. 1972, 5, 271.

(22) Markvardsen, A. J.; David, W. I. F.; Johnston, J. C.; Shankand, K., Acta Crystallographica Section A 2001, 57, 47-54.

(23) Dollase, W. A., J. Appl. Crystallogr. 1986, 19, 267-272.

(24) Bruno, I. J.; Cole, J. C.; Kessler, M.; Jie, L. M., W.D.S; Purkis, L. H.; Smith, B. R., Taylor, R.; Cooper, R. I.; Harris, S. E.; Orpen, A. G., Journal of chemical information and computen sciences 2004, 44, 2133-2144.

(25) Coelho, A. A., Journal of Applied Crystallography 2003, 36, 86-95.

(26) Wolff, S. K.; Grimwood, D. J.; McKinnon, J. J.; Jayatilaka, D.; Spackman, M. A. explorer 2.1, 2007.

(27) Spackman, M. A.; Jayatilaka, D., Crystengcomm 2009, 11(1), 19-32.

(28) Spackman, M. A.; McKinnon, J. J., Crystengcomm 2002, 378-392.

(29) Weigel, D.; Beguemsi, T.; Garnier, P.; Berar, J. F., Journal of Solid State Chemistry 1978, 23(3-4), 241-251.

(30) Salud, J.; Barrio, M.; Lopez, D. O.; Tamarit, J. L.; Alcobe, X., Journal of Applied Crystallography 1998, 31, 748-757.

(31) Cliffe, M. J.; Goodwin, A. L., J. Appl. Crystallogr. 2012, 45, 1321-1329.

(32) Kaminski, W. WinTensor ( http://cad4.cpac.washington.edu/wintensorhome/wintensor.htm), 1.1; 2004.

(33) Nicolaï, B.; Rietveld, I. B.; Barrio, M.; Mahé, N.; Tamarit, J.-L.; Céolin, R.; Guéchot, C.; Teulon, J.-M., Structural Chemistry 2013, 24, 279-283.

(34) Allouchi, H.; Nicolaï, B.; Barrio, M.; Céolin, R.; Mahé, N.; Tamarit, J.-L.; Do, B.; Rietveld, I. B., Crystal Growth \& Design 2014, 14, 1279-1286.

(35) Nicolaï, B.; Mahé, N.; Céolin, R.; Rietveld, I. B.; Barrio, M.; Tamarit, J.-L., Structural Chemistry 2011, 22, 649-659. 


\section{Tables}

Table 1. Crystal structure and refinement data at $298 \mathrm{~K}$ of triethylenetetramine dihydrochloride forms I and II

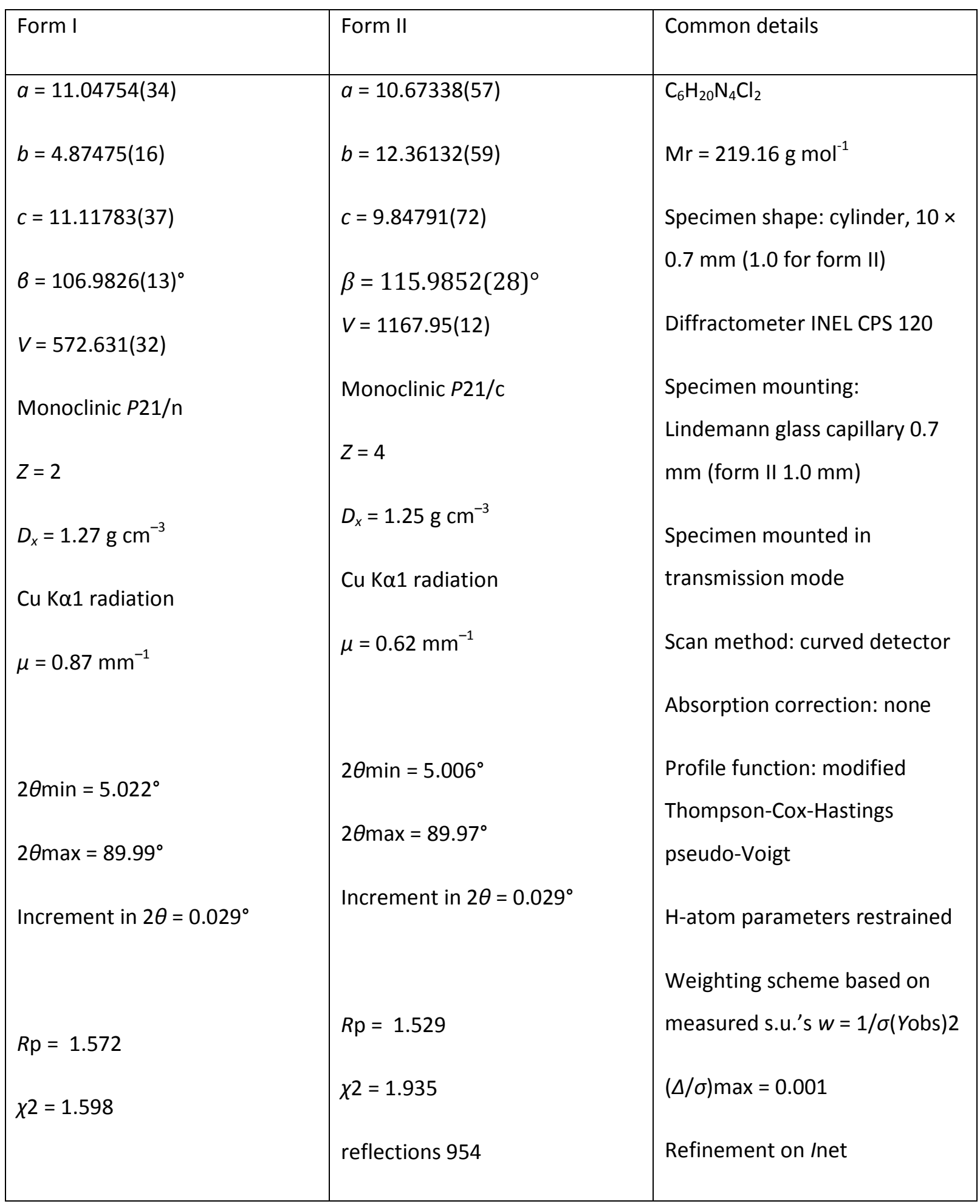




\begin{tabular}{|l|l|l|}
\hline reflections 471 & parameters 220 & Crystal structure - form I \\
parameters 88 & restraints 84 & \\
restraints 42 & & \\
& & \\
\hline
\end{tabular}


Table 2. Lattice parameters for triethylenetetramine dihydrochloride form I, form II, and its dihydrate as a function of the temperature ${ }^{a}$

\begin{tabular}{|c|c|c|c|c|c|}
\hline$T(K)$ & $a(\AA)$ & $b(\AA)$ & $c(\AA)$ & $\beta\left(1^{\circ}\right)$ & $V\left(\AA^{3}\right)$ \\
\hline \multicolumn{6}{|c|}{ Form I } \\
\hline 293 & 11.059 & 4.879 & 11.128 & 107.005 & 574.27 \\
\hline 290 & 11.058 & 4.878 & 11.126 & 107.014 & 573.89 \\
\hline 260 & 11.052 & 4.875 & 11.121 & 107.064 & 572.78 \\
\hline 230 & 11.048 & 4.871 & 11.116 & 107.105 & 571.78 \\
\hline 200 & 11.044 & 4.868 & 11.114 & 107.149 & 570.93 \\
\hline 150 & 11.035 & 4.863 & 11.106 & 107.223 & 569.29 \\
\hline 120 & 11.031 & 4.860 & 11.102 & 107.251 & 568.48 \\
\hline 320 & 11.059 & 4.881 & 11.125 & 106.968 & 575.067 \\
\hline 350 & 11.067 & 4.887 & 11.132 & 106.912 & 576.05 \\
\hline 380 & 11.074 & 4.891 & 11.136 & 106.865 & 577.15 \\
\hline 385 & 11.075 & 4.892 & 11.138 & 106.862 & 577.53 \\
\hline 390 & 11.075 & 4.893 & 11.139 & 106.857 & 577.67 \\
\hline \multicolumn{6}{|c|}{ Form II } \\
\hline 293 & 10.679 & 12.364 & 9.863 & 116.001 & 1170.47 \\
\hline 293 & 10.684 & 12.366 & 9.880 & 116.039 & 1172.87 \\
\hline 225 & 10.663 & 12.311 & 9.849 & 115.896 & 1163.11 \\
\hline 250 & 10.670 & 12.331 & 9.863 & 115.945 & 1167.03 \\
\hline
\end{tabular}




\begin{tabular}{|c|c|c|c|c|c|}
\hline 275 & 10.677 & 12.351 & 9.874 & 115.987 & 1170.52 \\
\hline 320 & 10.695 & 12.388 & 9.896 & 116.030 & 1178.16 \\
\hline 340 & 10.701 & 12.406 & 9.926 & 116.004 & 1184.39 \\
\hline 293 & 10.691 & 12.372 & 9.880 & 116.025 & 1174.36 \\
\hline 360 & 10.703 & 12.442 & 9.876 & 116.154 & 1180.54 \\
\hline 370 & 10.715 & 12.452 & 9.895 & 116.244 & 1184.21 \\
\hline 375 & 10.711 & 12.459 & 9.917 & 116.186 & 1187.55 \\
\hline \multicolumn{6}{|c|}{ dihydrate } \\
\hline 200 & 4.721 & 10.654 & 13.007 & 93.210 & 653.21 \\
\hline 250 & 4.731 & 10.677 & 13.016 & 93.188 & 656.46 \\
\hline 275 & 4.736 & 10.688 & 13.022 & 93.177 & 658.18 \\
\hline 300 & 4.742 & 10.701 & 13.024 & 93.158 & 659.86 \\
\hline 300 & 4.742 & 10.703 & 13.024 & 93.154 & 660.01 \\
\hline
\end{tabular}

${ }^{\mathrm{a}}$ The Rietveld refinement and Pawley refinement led to the same results within error, therefore only the Pawley results have been reported here. 
Table 3. Thermal expansion tensor eigenvalues and eigenvectors obtained for forms I and II, and the dehydrate of triethylenetetramine dihydrochloride

\begin{tabular}{|c|c|c|c|c|c|}
\hline \multicolumn{4}{|c|}{ Eigenvectors $^{\mathrm{a}}$} & \multicolumn{2}{|c|}{ Eigenvalues $\left(\mathrm{MK}^{-1}\right)$} \\
\hline & $a$ & $b$ & c & & \\
\hline \multicolumn{6}{|c|}{ Form I } \\
\hline $\mathbf{e}_{1}$ & 0.691 & 0 & -0.723 & $\alpha_{11}$ & $3.80(20)$ \\
\hline$e_{2}$ & 0 & -1 & 0 & $\alpha_{22}$ & $24.91(80)$ \\
\hline $\mathbf{e}_{3}$ & 0.719 & 0 & 0.695 & $\alpha_{33}$ & $31.78(32)$ \\
\hline \multicolumn{6}{|c|}{ Form II } \\
\hline $\mathbf{e}_{1}$ & -0.727 & 0 & -0.687 & $\alpha_{11}$ & $4.5(4.8)$ \\
\hline $\mathbf{e}_{2}$ & -0.545 & 0 & 0.838 & $\alpha_{22}$ & $47.0(5.0)$ \\
\hline $\mathbf{e}_{3}$ & 0 & 1 & 0 & $\alpha_{33}$ & $80.5(3.4)$ \\
\hline \multicolumn{6}{|c|}{ dihydrate } \\
\hline$e_{1}$ & -0.288 & 0 & -0.958 & $\alpha_{11}$ & $13.0(8)$ \\
\hline $\mathbf{e}_{2}$ & 0 & -1 & 0 & $\alpha_{22}$ & $43.8(5)$ \\
\hline $\mathbf{e}_{3}$ & 0.998 & 0 & 0.060 & $\alpha_{33}$ & $44.6(5)$ \\
\hline
\end{tabular}

as a function of the unit cell parameters 
Table 4. Torsion angles $\left(^{\circ}\right)$ of triethylenetetramine dichloride in forms $\mathrm{I}, \mathrm{II}$, and the dihydrate

\begin{tabular}{|l|l|l|l|}
\hline Torsion & form I & form II & dihydrate \\
\hline N1-C1-C2-N2 & $-73.7(3)$ & $74.5(1.3)$ & $178.83(9)$ \\
\hline C1-C2-N2-C3 & $172.9(3)$ & $-159.1(1.1)$ & $177.80(9)$ \\
\hline C2-N2-C3-C4* & $-177.3(3)$ & $81.7(1.2)$ & $-179.63(9)$ \\
\hline N2-C3-C4-N3* & $-180.00(3)$ & $44.7(1.6)$ & $-180.00(9)$ \\
\hline C3-C4-N3-C5* & $177.3(3)$ & $-163.5(1.2)$ & $179.63(9)$ \\
\hline C4-N3-C5-C6* & $-172.9(3)$ & $-56.5(1.6)$ & $-177.80(9)$ \\
\hline N3-C5-C6-N4* & $73.7(3)$ & $-76.1(1.4)$ & $-178.83(9)$ \\
\hline
\end{tabular}

*because of the symmetry in form I and the dihydrate $\mathrm{C} 4=\mathrm{C} 3, \mathrm{~N} 3=\mathrm{N} 2, \mathrm{C} 5=\mathrm{C} 2, \mathrm{C} 6=\mathrm{C} 1$ and $\mathrm{N} 4=\mathrm{N} 1$ 
Table 5. Hydrogen bonds in form I, form II and the dihydrate in the asymmetric unit ${ }^{\mathrm{a}}$

\begin{tabular}{|c|c|c|c|c|}
\hline & \multicolumn{3}{|c|}{ Distance $(\AA)$} & \multirow{2}{*}{$\begin{array}{l}\text { Angle }\left(^{\circ}\right) \\
D-H \cdots A\end{array}$} \\
\hline & $\mathrm{D}-\mathrm{H}$ & $\mathrm{H} \cdots \mathrm{A}$ & $D \cdots A$ & \\
\hline \multicolumn{5}{|l|}{ Form I } \\
\hline $\mathrm{N} 1-\mathrm{HN} 1 \mathrm{c} \cdots \mathrm{N} 2^{\mathrm{i}}$ & $0.92(2)$ & $2.03(2)$ & $2.917(5)$ & $161.6(1.1)$ \\
\hline $\mathrm{N} 1-\mathrm{HN} 1 \mathrm{a} \cdots \mathrm{Cl} \mathrm{Cl}^{\mathrm{i}}$ & $0.887(10)$ & $2.57(10)$ & $3.133(3)$ & $169.3(1.0)$ \\
\hline $\mathrm{N} 1-\mathrm{HN} 1 \mathrm{~b} \cdots \mathrm{Cl} \mathrm{I}^{\mathrm{iii}}$ & $0.928(13)$ & $2.219(12)$ & $3.135(4)$ & $168.8(1.0)$ \\
\hline $\mathrm{N} 2-\mathrm{HN} 1 \mathrm{~b} \cdots \mathrm{Cli}$ & $0.829(85)$ & $2.556(95)$ & $3.374(4)$ & $169.50(28)$ \\
\hline $\mathrm{C} 1-\mathrm{H} 1 \mathrm{a} \cdots \mathrm{Cl} \mathrm{I}^{\mathrm{iii}}$ & $0.958(11)$ & $2.852(13)$ & $3.739(3)$ & $154.60(97)$ \\
\hline \multicolumn{5}{|l|}{ Form II } \\
\hline $\mathrm{N} 1-\mathrm{HN} 1 \mathrm{a} \cdots \mathrm{Cl} 1^{\mathrm{iv}}$ & 0.89 & 2.506 & 3.309 & 150.40 \\
\hline $\mathrm{N} 1-\mathrm{HN} 1 \mathrm{~b} \cdots \mathrm{Cl} 1^{v}$ & $0.95(4)$ & $2.21(5)$ & $3.11(2)$ & $158(4)$ \\
\hline $\mathrm{N} 2-\mathrm{HN} 2 \cdots \mathrm{Cl} 1^{\mathrm{ii}}$ & $0.80(5)$ & $2.51(4)$ & $3.297(16)$ & $165(4)$ \\
\hline $\mathrm{N} 3-\mathrm{HN} 3 \cdots \mathrm{Cl}^{\mathrm{iv}}$ & $0.78(7)$ & $3.35(5)$ & $3.208(18)$ & $93(5)^{b}$ \\
\hline $\mathrm{N} 3-\mathrm{HN} 3 \cdots \mathrm{Cl} 2^{\mathrm{vi}}$ & $0.78(7)$ & $2.48(6)$ & $3.20(2)$ & $153(6)$ \\
\hline $\mathrm{C} 4-\mathrm{H} 4 \mathrm{~b} \cdots \mathrm{Cl} 2^{\mathrm{vi}}$ & $0.98(5)$ & $2.74(5)$ & $3.540(1)$ & $138(4)$ \\
\hline $\mathrm{N} 4-\mathrm{HN} 4 \mathrm{c} \cdots \mathrm{Cl} 2^{\mathrm{vi}}$ & $0.89(5)$ & $2.98(5)$ & $3.42(2)$ & $112(3)$ \\
\hline $\mathrm{N} 4-\mathrm{HN} 4 \mathrm{~b} \cdots \mathrm{Cl} 2^{\mathrm{vii}}$ & $0.90(5)$ & $2.74(4)$ & $3.317(16)$ & $123(4)$ \\
\hline \multicolumn{5}{|l|}{ Dihydrate } \\
\hline $\mathrm{N} 1-\mathrm{H} 3 \cdots \mathrm{Cl}^{\mathrm{viii}}$ & $0.875(17)$ & $2.466(18)$ & $3.2993(13)$ & $159.3(1.5)$ \\
\hline $\mathrm{N} 1-\mathrm{H} 4 \cdots \mathrm{Cl}^{\mathrm{ix}}$ & $0.915(18)$ & $2.319(18)$ & $3.1911(14)$ & $159.2(1.5)$ \\
\hline
\end{tabular}




\begin{tabular}{|l|l|l|l|l|}
\hline $\mathrm{N} 1 \cdots \mathrm{Cl}^{\mathrm{ii}}$ & & & $3.388(1)^{\mathrm{b}}$ & \\
\hline $\mathrm{N} 1-\mathrm{H} 5 \cdots \mathrm{O}^{\mathrm{x}}$ & $0.915(16)$ & $1.876(16)$ & $2.7593(15)$ & $161.8(1.4)$ \\
\hline $\mathrm{N} 2-\mathrm{H} 6 \cdots \mathrm{Cl}^{\mathrm{xi}}$ & $0.831(17)$ & $2.702(18)$ & $3.5287(12)$ & $173.3(1.4)$ \\
\hline $\mathrm{O} 1-\mathrm{H} 2 \cdots \mathrm{N2}^{\mathrm{ii}}$ & $0.874(19)$ & $1.880(16)$ & $2.7485(14)$ & $172.1(1.8)$ \\
\hline $\mathrm{O} 1-\mathrm{H} 1 \cdots \mathrm{Cl}^{\mathrm{xii}}$ & $0.759(19)$ & $2.492(19)$ & $3.2467(13)$ & $173.2(19)$ \\
\hline
\end{tabular}

Symmetry codes: (i) $x, y-1, z$; (ii) $x, y, z$; (iii) $-x+1 / 2, y-1 / 2,-z+1.5$; (iv) $-x+1,-y+1,-z+1$; (v) $-x+1, y+$ $1 / 2,-z+1 / 2$; (vi) $-x+1, y-1 / 2,-z+1 / 2$; (vii) $x-1, y, z$; (viii) $-x,-y+1,-z+1$; (ix) $x-1, y, z$; (x) $-x-1, y+1 / 2,-z+$ 1.5; (xi) $x-1,-y+1.5, z+1 / 2 ;(x i i)-x-1 ;-y+1,-z+1$;

${ }^{a}$ Both the dihydrate and form I have only half a TETA molecule in the asymmetric unit

${ }^{b}$ This may not be a hydrogen bond in accordance with its definition, but the donor - acceptor distance and the fact that the acceptor $\mathrm{Cl}^{-}$is charged imply nevertheless the presence of an electrostatic interaction 


\section{For Table of Contents us only}

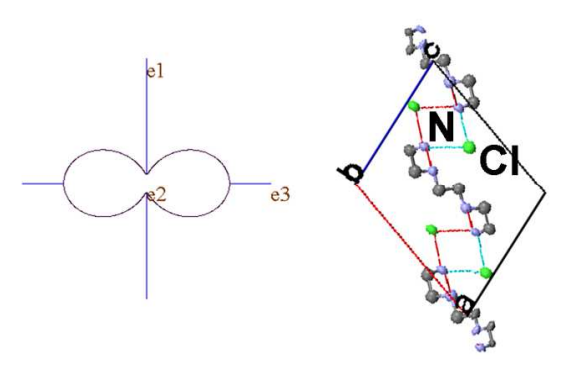

Triethylenetetramine dihydrochloride forms strong ionic interactions, such as the diamond patterns with $\mathrm{NH}_{3}{ }^{+}$and $\mathrm{Cl}^{-}$as shown, that clearly affect the thermal expansion of the crystal. In combination with configurational versatility and a multitude of hydrogen bonds, it leads to several distinct crystal structures. 


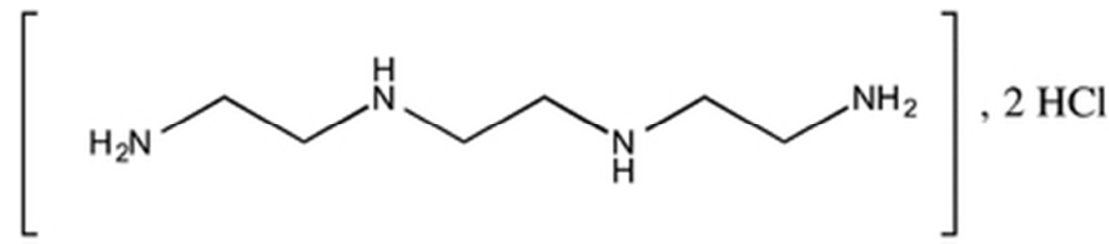

Chemical structure of triethylenetetramine dihydrochloride $17 \times 3 \mathrm{~mm}(600 \times 600 \mathrm{DPI})$ 


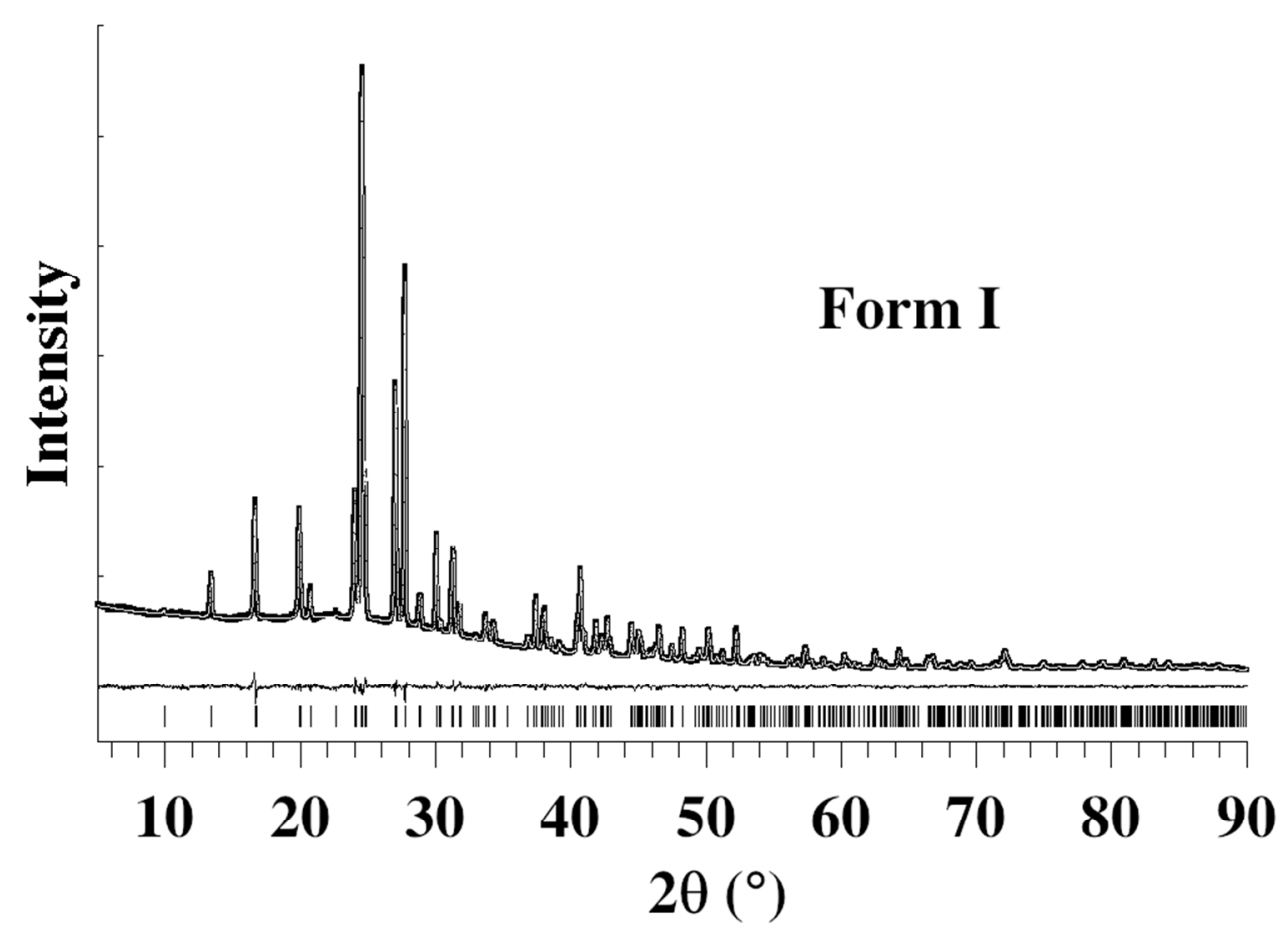

Results of the structure resolutions by X-ray powder diffraction a. Rietveld refinements against the powder diffraction patterns b. Crystal structure of form I c. Crystal structure of form II. Hydrogen atoms omitted for clarity.

$91 \times 66 \mathrm{~mm}(288 \times 288 \mathrm{DPI})$ 
1

2

3

4

5

6

7

8

9

10

11

12

13

14

15

16

17

18

19

20

21

22

23

24

25

26

27

28

29

30

31

32

33

34

35

36

37

38

39

40

41

42

43

44

45

46

47

48

49

50

51

52

53

54

55

56

57

58

59

60

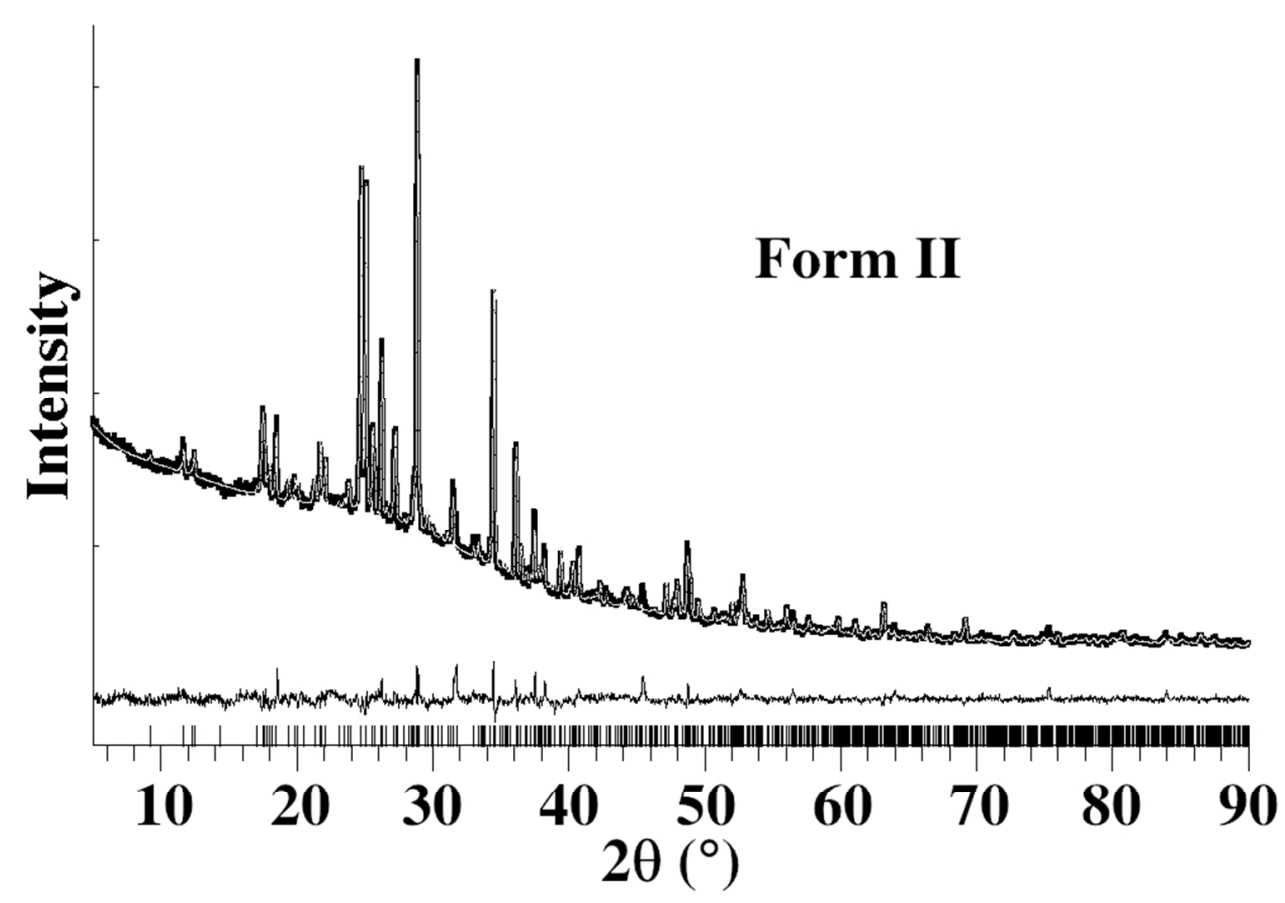

Results of the structure resolutions by X-ray powder diffraction a. Rietveld refinements against the powder diffraction patterns b. Crystal structure of form I c. Crystal structure of form II. Hydrogen atoms omitted for clarity.

$90 \times 63 \mathrm{~mm}(288 \times 288 \mathrm{DPI})$ 

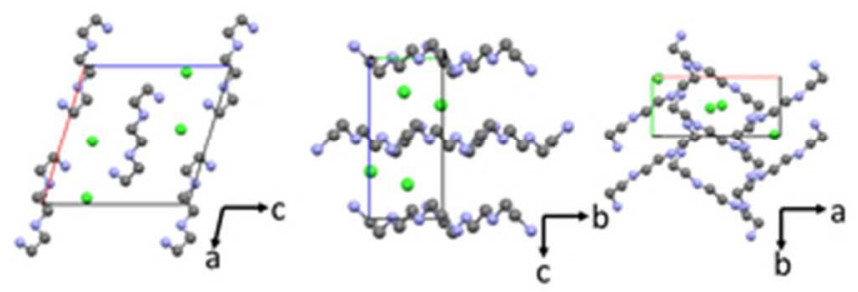

Results of the structure resolutions by X-ray powder diffraction a. Rietveld refinements against the powder diffraction patterns b. Crystal structure of form I c. Crystal structure of form II. Hydrogen atoms omitted for clarity.

$28 \times 9 \mathrm{~mm}(300 \times 300 \mathrm{DPI})$ 
Results of the structure resolutions by X-ray powder diffraction a. Rietveld refinements against the powder diffraction patterns b. Crystal structure of form I c. Crystal structure of form II. Hydrogen atoms omitted for clarity.

$28 \times 9 \mathrm{~mm}(300 \times 300 \mathrm{DPI})$ 


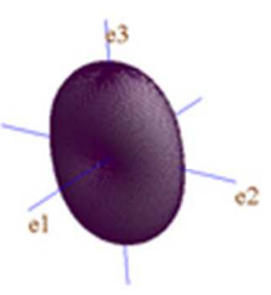

Form I

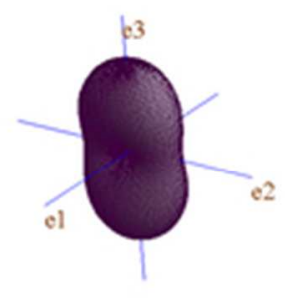

Form II

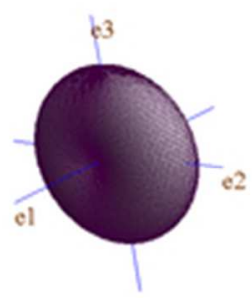

dihydrate

Graphical representation of the thermal expansion tensors of forms I, II, and the dihydrate at $300 \mathrm{~K}$ $31 \times 12 \mathrm{~mm}$ (300 x 300 DPI) 


1
2
3
4
5
6
7
8
9
10
11
12
13
14
15
16
17
18
19
20
21
22
23
24
25
26
27
28
29
30
31
32
33
34
35
36
37
38
39
40
41
42
43
44
45
46
47
48
49
50
51
52
53
54
55
56
57
58
60

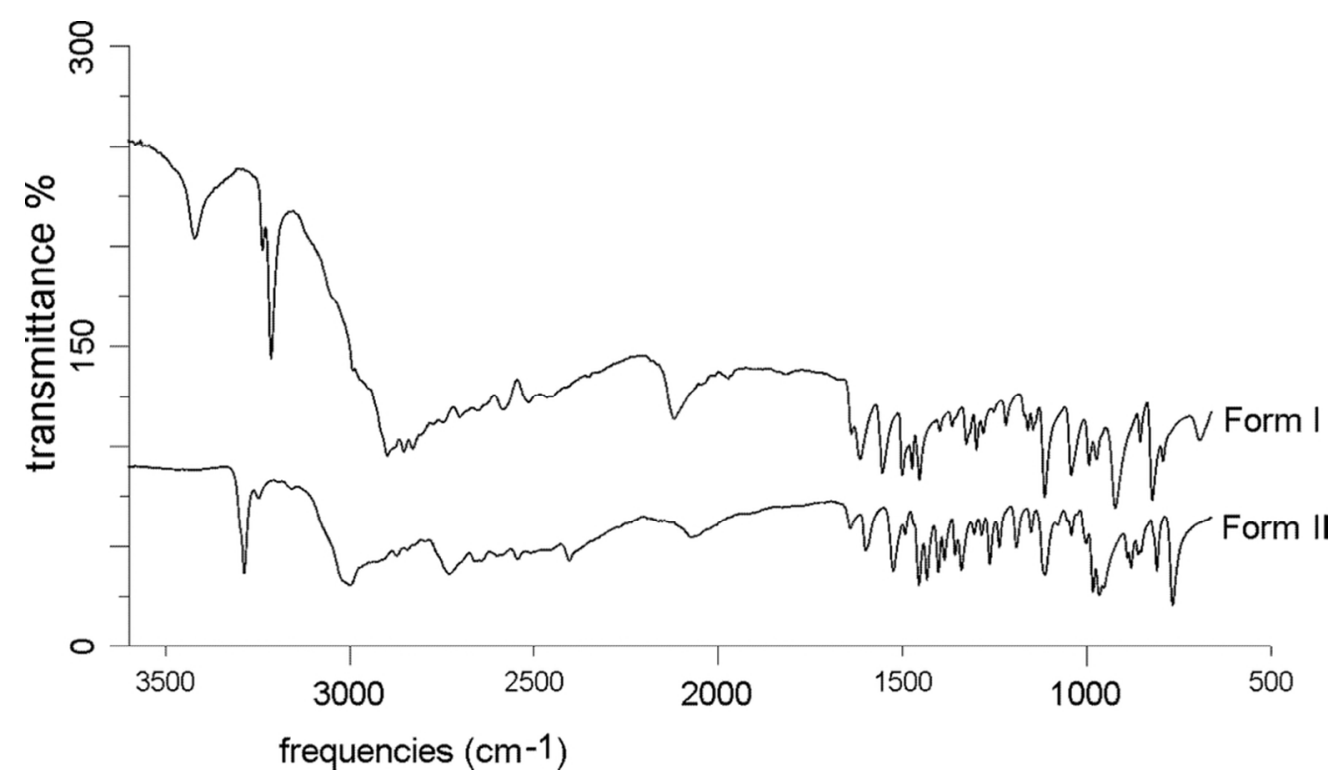

Infrared transmittance spectra of the two TETA.2HCl polymorphs I and II. Spectra are shifted for clarity $47 \times 27 \mathrm{~mm}(600 \times 600 \mathrm{DPI})$ 

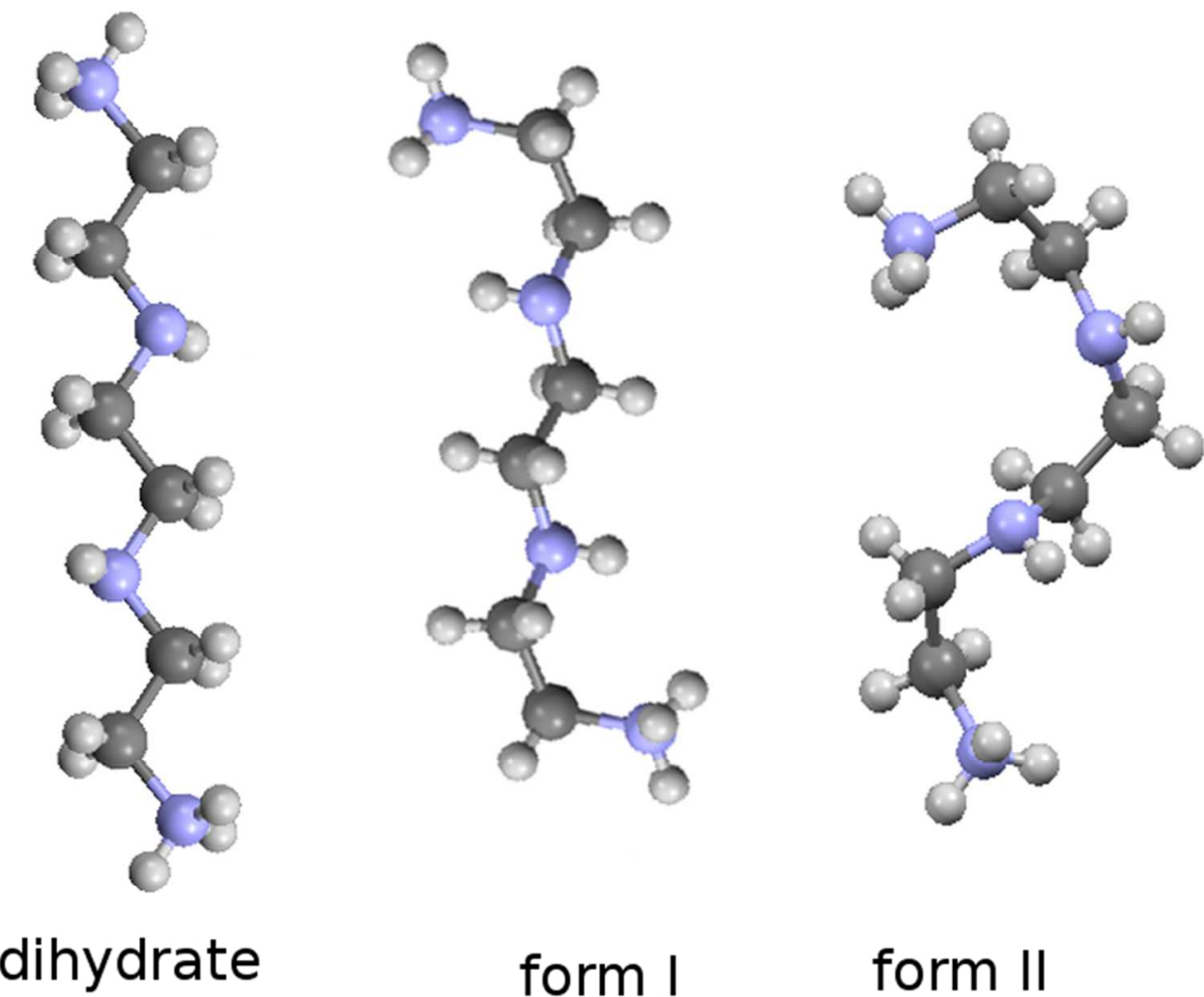

form I

form II

Conformations of TETA in the dihydrate (left-hand side), form I (center), and form II (right-hand side) $82 \times 66 \mathrm{~mm}(300 \times 300$ DPI $)$ 


1
2
3
4
5
6
7
8
9
10
11
12
13
14
15
16
17
18
19
20
21
22
23
24
25
26
27
28
29
30
31
32
33
34
35
36
37
38
39
40
59
50
50
49
50
51
52
53
44
54

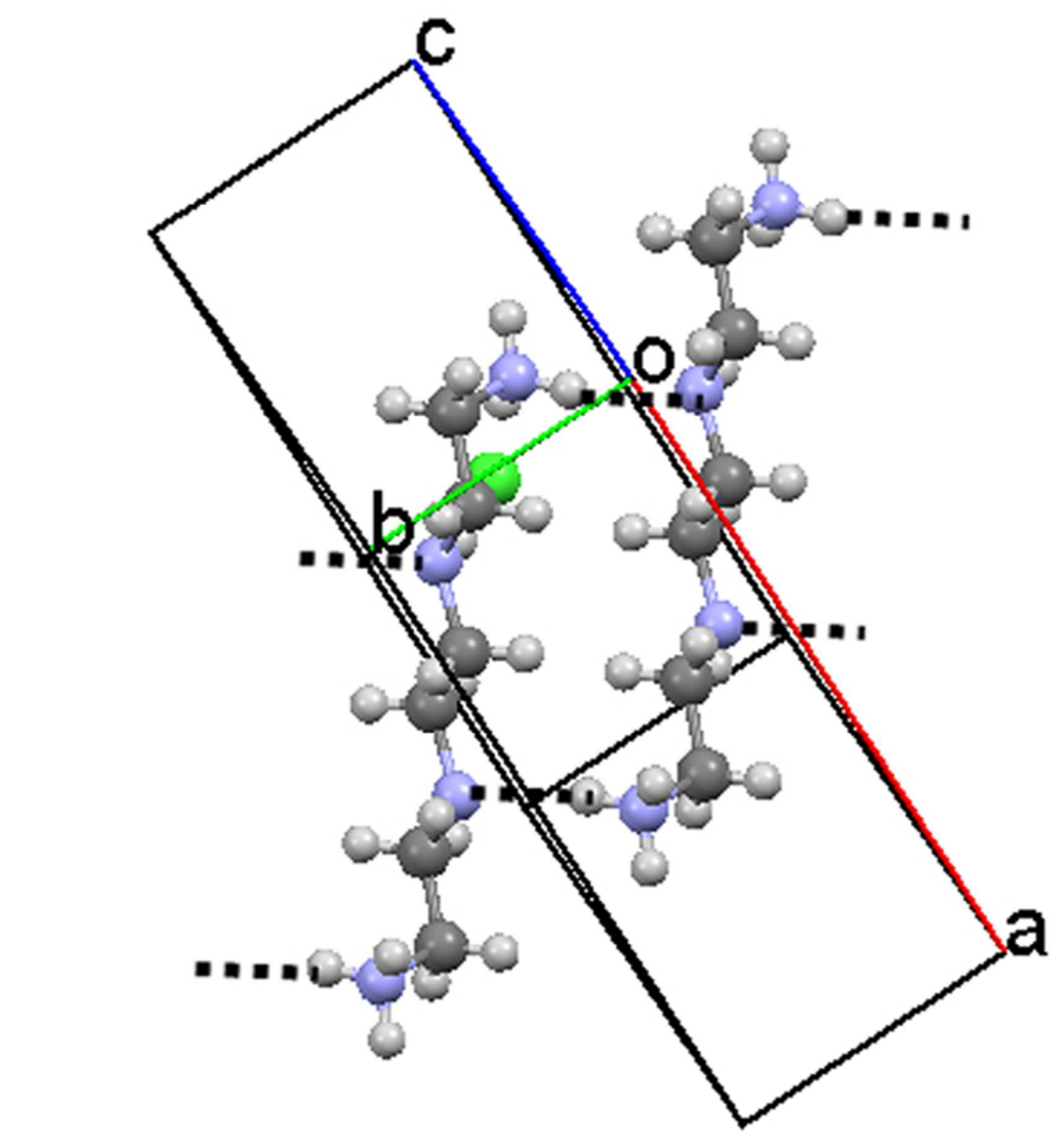

Hydrogen-bond patterns in form I a. between TETA molecules $b$. Ionic interactions between chloride ions and ammonium groups on TETA molecules (graph set R24(8)) c. Hydrogen bonds and other interactions around the chloride ion

$50 \times 61 \mathrm{~mm}(300 \times 300 \mathrm{DPI})$ 


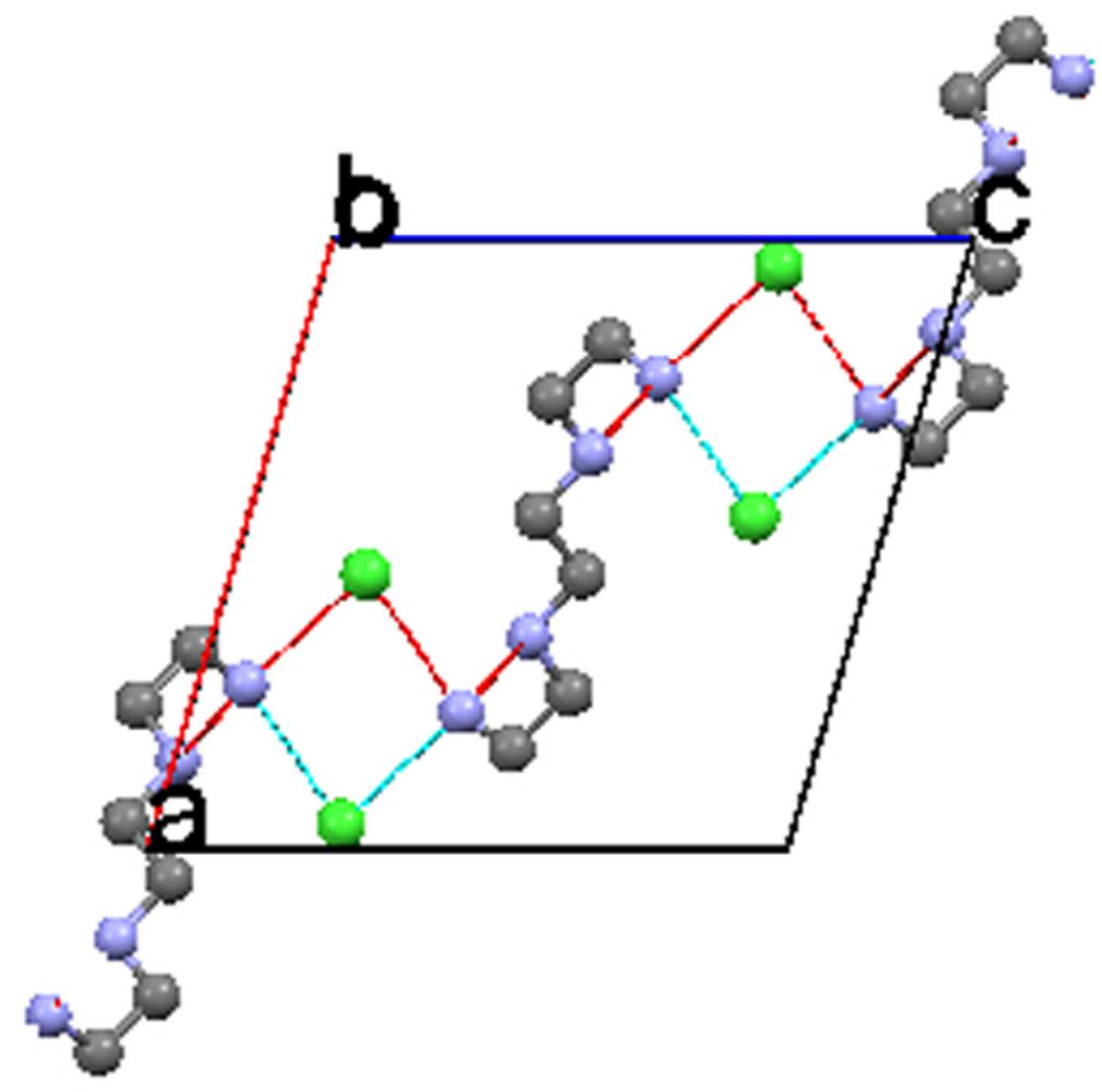

Hydrogen-bond patterns in form I a. between TETA molecules b. Ionic interactions between chloride ions and ammonium groups on TETA molecules (graph set R24(8)) c. Hydrogen bonds and other interactions around the chloride ion

$39 \times 39 \mathrm{~mm}(300 \times 300$ DPI $)$ 
Hydrogen-bond patterns in form I a. between TETA molecules b. Ionic interactions between chloride ions and ammonium groups on TETA molecules (graph set R24(8)) c. Hydrogen bonds and other interactions around the chloride ion $50 \times 23 \mathrm{~mm}(300 \times 300 \mathrm{DPI})$ 


1
2
3
4
5
6
7
8
9
10
11
12
13
14
15
16
17
18
19
20
21
22
23
24
25
26
27
28
29
30
31
32
33
34
35
36
37
38
39
40
41
42
43
44
45
46
47
48
49
50
51
52
53
54
55
56
57
58
60

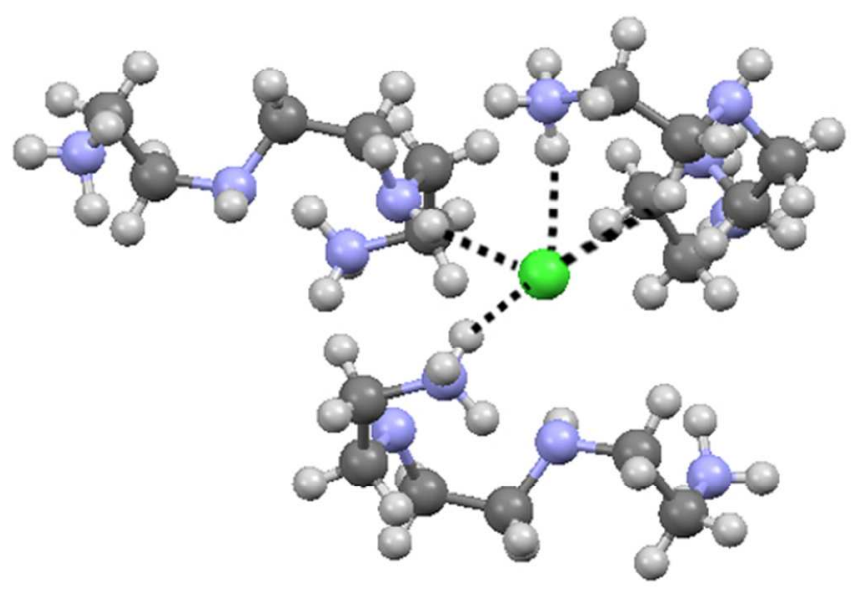

Ionic and hydrogen-bond interactions of $\mathrm{Cl} 1$ in form II. $70 \times 37 \mathrm{~mm}(300 \times 300 \mathrm{DPI})$ 

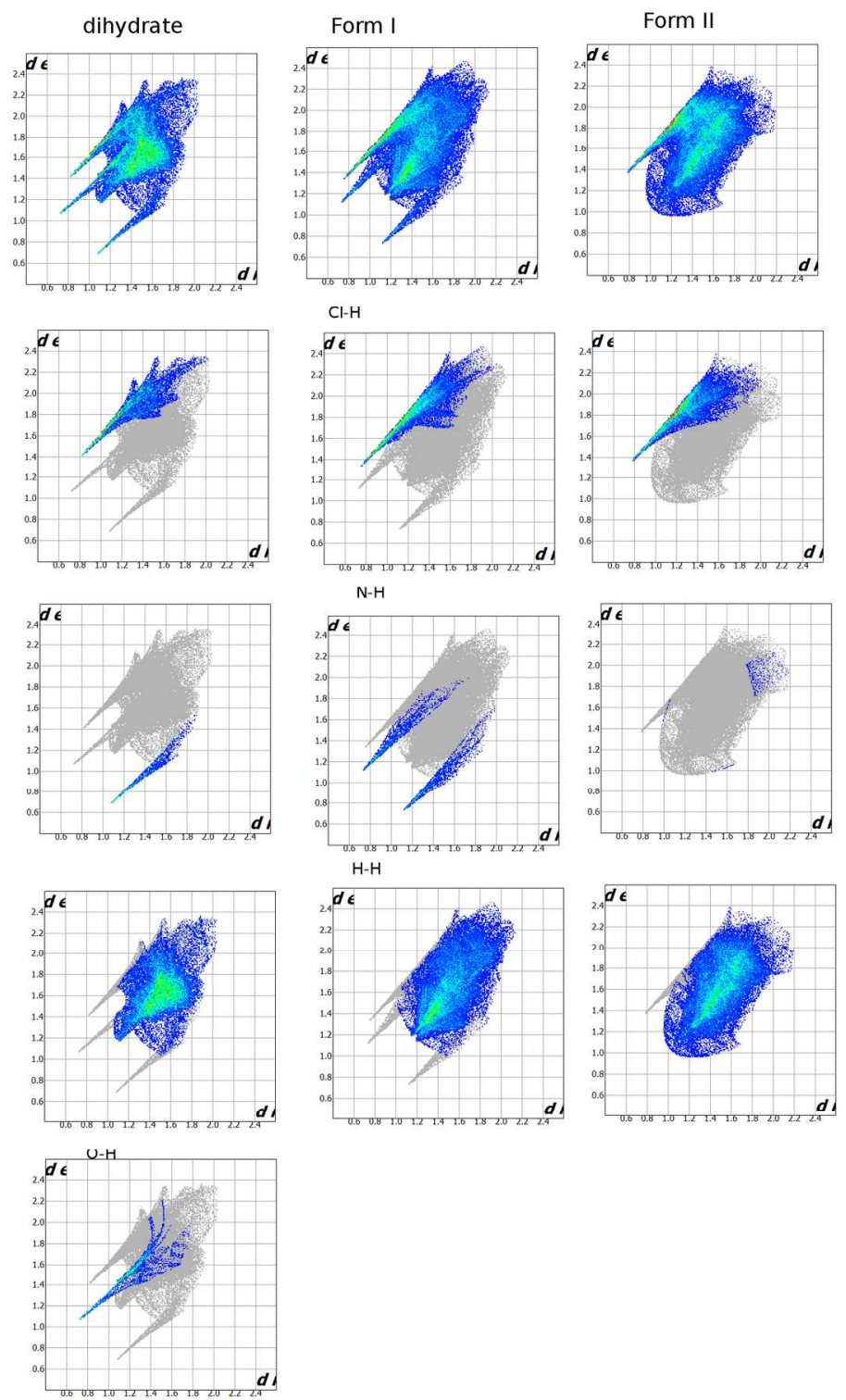

Fingerprint plots of the TETA molecule in the dihydrate, in form I and in form II. From top to bottom: all intermolecular interactions together, $\mathrm{Cl} \cdots \mathrm{H}$ interactions, $\mathrm{N} \cdots \mathrm{H}, \mathrm{H} \cdots \mathrm{H}$, and $\mathrm{O} \cdots \mathrm{H}$ interactions. The di, de occurrence increases from deep blue to light blue. $136 \times 225 \mathrm{~mm}(300 \times 300 \mathrm{DPI})$ 

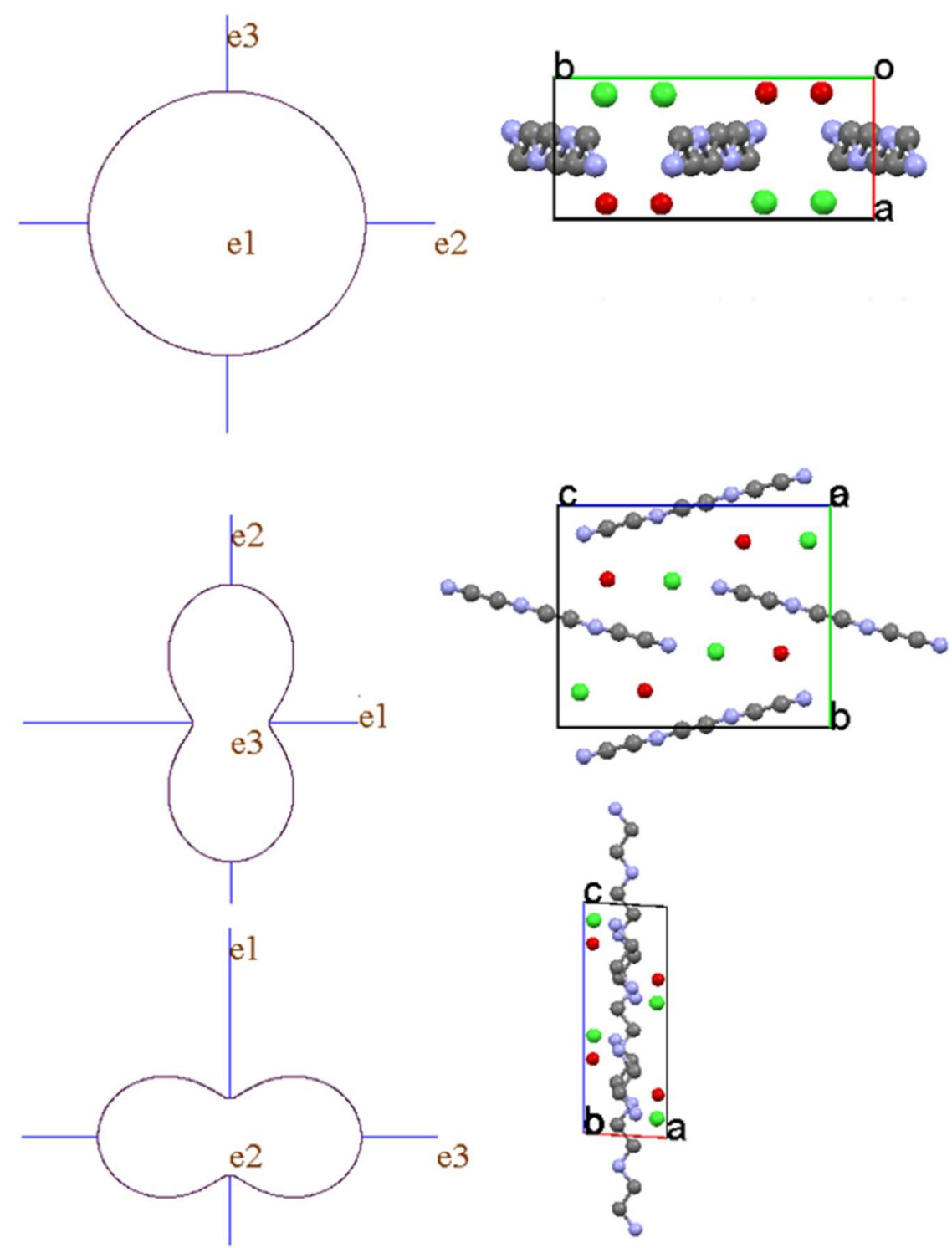

Projections of the thermal expansion tensors in relation to the unit cell a. for the dihydrate, b. for form I, and c. for form II. Hydrogen atoms have been omitted for clarity. $64 \times 84 \mathrm{~mm}(300 \times 300$ DPI $)$ 
Projections of the thermal expansion tensors in relation to the unit cell a. for the dihydrate, b. for form I, and c. for form II. Hydrogen atoms have been omitted for clarity. $82 \times 137 \mathrm{~mm}(300 \times 300 \mathrm{DPI})$ 

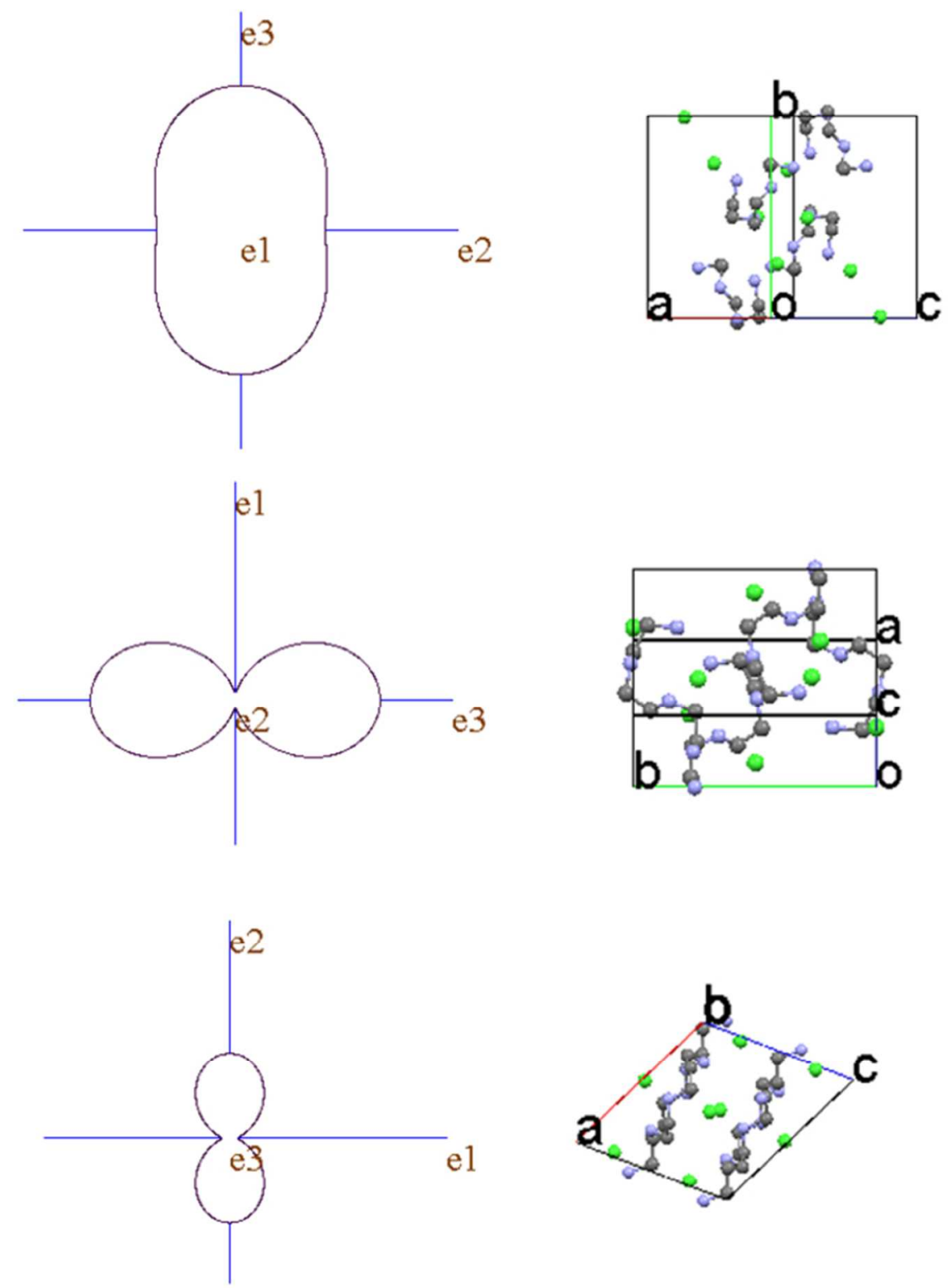

Projections of the thermal expansion tensors in relation to the unit cell a. for the dihydrate, b. for form I, and c. for form II. Hydrogen atoms have been omitted for clarity. $64 \times 84 \mathrm{~mm}(300 \times 300 \mathrm{DPI})$ 
1

2

3

4

5

6

7

8

9

10

11

12

13

14

15

16

17

18

19

20

21

22

23

24

25

26

27

28

29

30

31

32

33

34

35

36

37

38

39

40

41

42

43

44

45

46

47

48

49

50

51

52

53

54

55

56

57

58

59

60

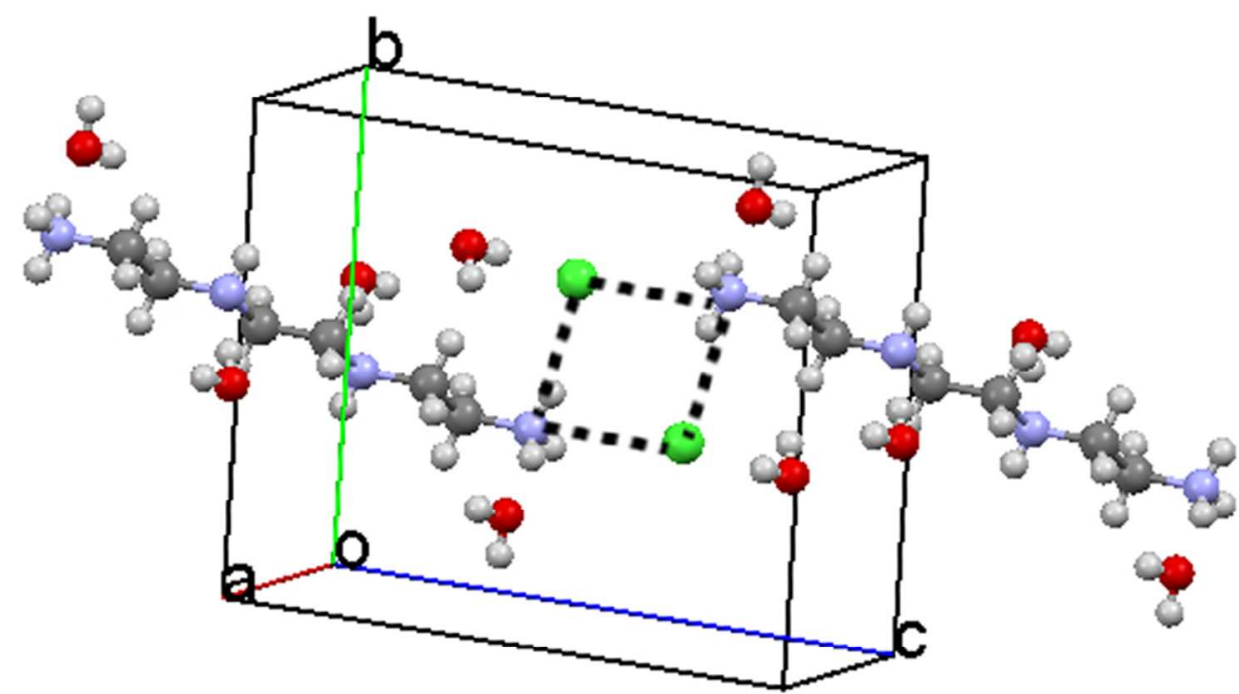

Diamond shape pattern in the dihydrate made up by the ionic interaction involving two chloride ions and two ammonium end groups.

$70 \times 44 \mathrm{~mm}(300 \times 300 \mathrm{DPI})$ 
39

40
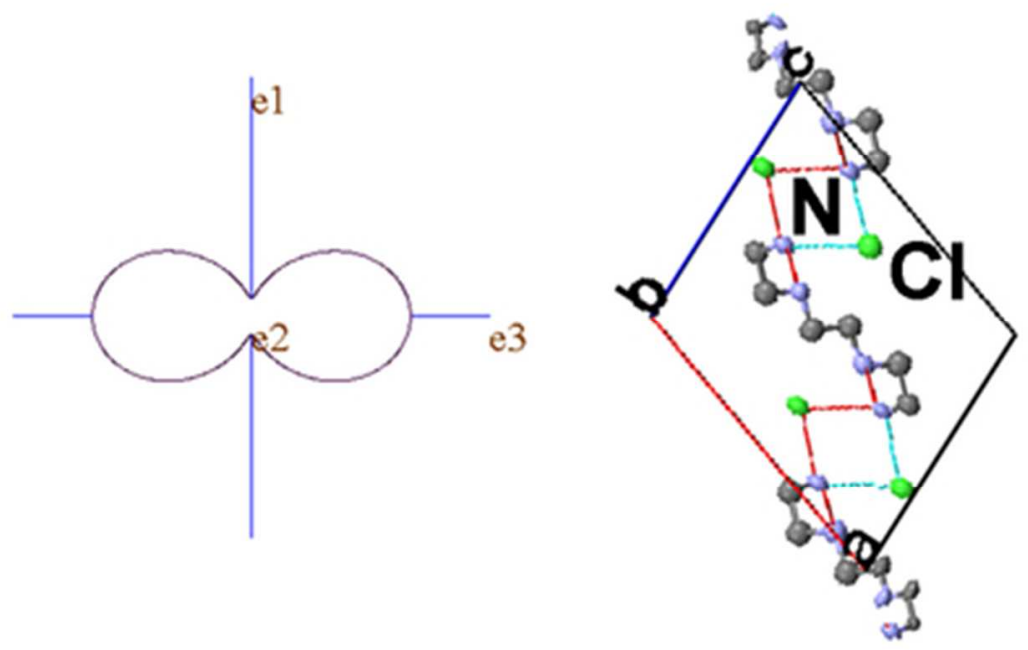

Triethylenetetramine dihydrochloride forms strong ionic interactions, such as the diamond patterns with $\mathrm{NH} 3+$ and $\mathrm{Cl}-$ as shown, that clearly affect the thermal expansion of the crystal. In combination with configurational versatility and a multitude of hydrogen bonds, it leads to several distinct crystal structures. $34 \times 21 \mathrm{~mm}$ (300 x 300 DPI) 